\title{
Chlorophyll and carbohydrate metabolism in developing silique and seed are prerequisite to seed oil content of Brassica napus L.
}

\author{
Shuijin Hua ${ }^{1 *}$, Zhong-Hua Chen ${ }^{2}$, Yaofeng Zhang ${ }^{1}$, Huasheng Yu ${ }^{1}$, Baogang Lin ${ }^{1}$ and Dongqing Zhang ${ }^{1 *}$
}

\begin{abstract}
Background: Although the seed oil content in canola is a crucial quality determining trait, the regulatory mechanisms of its formation are not fully discovered. This study compared the silique and seed physiological characteristics including fresh and dry weight, seed oil content, chlorophyll content, and carbohydrate content in a high oil content line $(\mathrm{HOCL})$ and a low oil content line (LOCL) of canola derived from a recombinant inbred line in 2010, 2011, and 2012. The aim of the investigation is to uncover the physiological regulation of silique and seed developmental events on seed oil content in canola.

Results: On average, $83 \%$ and $86 \%$ of silique matter while $69 \%$ and $63 \%$ of seed matter was produced before 30 days after anthesis (DAA) in HOCL and LOCL, respectively, over three years. Furthermore, HOCL exhibited significantly higher fresh and dry matter at most developmental stages of siliques and seeds. From 20 DAA, lipids were deposited in the seed of $\mathrm{HOCL}$ significantly faster than that of $\mathrm{LOCL}$, which was validated by transmission electron microscopy, showing that HOCL accumulates considerable more oil bodies in the seed cells. Markedly higher silique chlorophyll content was observed in HOCL consistently over the three consecutive years, implying a higher potential of photosynthetic capacity in siliques of HOCL. As a consequence, HOCL exhibited significantly higher content of fructose, glucose, sucrose, and starch mainly at 20 to 45 DAA, a key stage of seed lipid deposition. Moreover, seed sugar content was usually higher than silique indicating the importance of sugar transportation from siliques to seeds as substrate for lipid biosynthesis. The much lower silique cellulose content in HOCL was beneficial for lipid synthesis rather than consuming excessive carbohydrate for cell wall.
\end{abstract}

Conclusions: Superior physiological characteristics of siliques in HOCL showed advantage to produce more photosynthetic assimilates, which were highly correlated to seed oil contents.

Keywords: Biomass; Brassica napus L; Carbohydrate; Chlorophyll content; Seed oil content

\section{Background}

Canola (Brassica napus L.) seed oil content is an important and intricate quantitative trait, which is regulated by many factors such as genetic control, developmental cues, and environmental influences (Cheema et al. 2001; Delourme et al. 2006; Rathke et al. 2006; Wang et al. 2010). Proteins and carbohydrates are two closely-related major reserves in developing canola seed during lipid biosynthesis (Wang et al. 2007a; Ekman et al. 2008). Carbohydrate, in the form of photosynthetic assimilates from green tissues such as

\footnotetext{
* Correspondence: sjhua1@163.com; dq_zhang@126.com

${ }^{1}$ Institute of Crop and Nuclear Technology Utilization, Zhejiang Academy of

Agricultural Sciences, Hangzhou 310021, P.R. China

Full list of author information is available at the end of the article
}

siliques and leaves, plays multiple roles in cellular metabolism. Firstly, carbohydrate such as sucrose produced by photosynthesis in green tissues is a precursor and essential substrate for fatty acid biosynthesis (Focks and Benning 1998). Thus, it implies that ample carbohydrates in canola siliques and seeds might be beneficial to higher seed oil content. Secondly, conversion of carbohydrate into lipids, proteins, and secondary metabolites such as fiber is an elaborate regulation system during seed development, which can greatly affect seed oil content (Ekman et al. 2008).

Lipid biosynthetic pathway at seed filling stage has been revealed in some plant species such as Arabidopsis thaliana, Glycine max L., and Brassica napus L. (Ruuska et al. 2002; Houston et al. 2009). As the starting point, 
sucrose is cleaved into fructose and glucose that take part in fatty acid metabolism (Baud and Lepiniec 2009; Hajduch et al. 2010). Thus, it emphasizes the essential role of those carbohydrates on the lipid biosynthesis in seeds of oil crops. Further, the crucial role of carbohydrate metabolism for seed development of oil crops such as soybean and canola was recently demonstrated by RNA transcript profiling, proteomic analysis, and functional studies of relevant genes (Hajduch et al. 2006; Andre et al. 2007; Agrawal et al. 2008; Houston et al. 2009).

In canola, the reproductive growth upon flower initiation becomes more dominant despite the vegetative growth is continuing. Its notable characteristics are the formation of more siliques and the senescence of old leaves at the lower stalk. At the end of flowering, siliques dominate the canopy of canola plants and become the major photosynthetic organ regardless of the existence of other green tissues (e.g. newly formed leaves at the base of branches and stems) (Berry and Spink 2006). Almost $60 \%$ of assimilates for seed development were derived from photosynthesis of siliques confirms the predominance of silique as a photosynthetic organ for seed development (Lewis and Thruling 1994; Gammelvind et al. 1996). Furthermore, the developing seed is directly connected with silique via funiculus (Stadler et al. 2005), hence silique might be the only organ that directly supplies marco- and micro-nutrients to the developing seed. Consequently, it is worthwhile to investigate the physiological roles of silique in seed oil accumulation. During last few decades, lots of efforts were elaborated on silique dehiscence (or pod shattering), which was directly related to seed disperses and yields (Jenkins et al. 1996; Child et al. 2003; Bennett et al. 2011). However, little work was conducted on the dynamic association between carbohydrates, chlorophyll content, and seed oil accumulation in siliques over long period of growth and across several seasons. Questions such as, whether the amount and composition of assimilates produced by silique can affect seed lipid accumulation, and whether the dynamic changes of assimilates correlate to the lipid content, biomass, and yield, still need to be addressed.

Previously, we employed a high oil content line (HOCL; $50.4 \%$ of oil content) and a low oil content line (LOCL; $41.4 \%$ of oil content) to evaluate the difference of macro-nutrients and carbohydrate content in aboveground tissues: flower, stem, and leaf. The result suggested that higher carbohydrate content and lower $\mathrm{N}$ content in those photosynthetic tissues might contribute to higher oil content in HOCL (Hua et al. 2012a). In the present study, dynamic changes of silique and seed weight of HOCL and LOCL were recorded to evaluate their growth characteristics. Seed oil content along with seed and silique ultrastructure of HOCL and LOCL were analyzed to elucidate the difference of seed oil deposition during seed development. Furthermore, chlorophyll content fructose, glucose, sucrose, starch, and cellulose were determined in both siliques and seeds of HOCL and LOCL. The correlation and factor analysis between seed oil content and these physiological indexes revealed the key roles of increasing silique chlorophyll content and seed starch content and reducing cellulose content during seed oil accumulation.

\section{Methods}

\section{Plant materials}

Field trials were conducted over three growth seasons in 2009-2010, 2010-2011, and 2011-2012, at the experimental station of Zhejiang Academy of Agricultural Sciences, Hangzhou, China. Seeds of two Recombinant Inbred Lines (RILs) with high and low oil content, developed from Zheshuang 6/Huyou 15, were sown in a seedling bed on October 3, 2009 and October 5, 2010 and 2011. After one month, seedlings with uniform growth were selected and transplanted to experimental plots and general field managements were conducted for all three trials. The soil type in the experimental station was loamy clay (loamy, mixed, and thermic Aeric Endoaquepts). Urea was evenly broadcasted in the soil at $150 \mathrm{~kg} \mathrm{ha}^{-1}$ before transplanting and an additional $75 \mathrm{~kg} \mathrm{ha}^{-1}$ urea was applied at the end of January for each season. During the three growth seasons, rainfall (1041.7, 1048.3, and $1217.5 \mathrm{~mm}$, respectively) in Hangzhou was sufficient for canola without irrigation.

\section{Experimental design and sampling}

The experiments employed a randomly complete block design, where two canola lines with contrasting seed oil content were used as two experimental treatments. Plants were grown in $20 \times 3.2 \mathrm{~m}$ plots with three replications for both HOCL and LOCL. Each plot consisted of eight rows with $0.35 \mathrm{~m}$ between rows and $0.20 \mathrm{~m}$ between plants. Plants were tied with colored cotton strings at main inflorescence and the data were recorded from 10 days after anthesis (DAA) till 65 DAA. Five plants were randomly sampled in the core area of each plot to minimize marginal effect.

\section{Oil content measurement}

The measurement of oil content was performed using a Shimadzu gas chromatography system (GC-2014, Japan) equipped with a flame ionization detector and a $30 \mathrm{~m}$ (length) $\times 0.25 \mathrm{~mm}$ (inner diameter) $\times 0.25 \mu \mathrm{m}$ (liquid membrane thickness) column (Supelco wax-10, Supelco) in 2010 and 2011 using fresh immature seed samples. They were frozen in liquid nitrogen, ground into fine powder. The extraction of fatty acids and conditions of gas chromatography using heptadecanoate as an internal 
standard were essentially as described by Hajduch et al. (2006) and $\mathrm{Mu}$ et al. (2008). Briefly, samples were initially extracted by $1 \mathrm{~mL}$ of $14 \%$ boron trifluoride with heptadecanoate as standard in toluene. $150 \mu \mathrm{L}$ standard in toluene and samples were incubated at $95^{\circ} \mathrm{C}$ for $90 \mathrm{~min}$ and shaking acutely with every $10 \mathrm{~min}$. After incubation and cooled to room temperature, samples were added into $1 \mathrm{~mL}$ of water and $3 \mathrm{~mL}$ of hexane. Tubes were shaken vigorously and centrifuged at $4000 \mathrm{rpm}$ for $5 \mathrm{~min}$. Top phase was transferred into another new tube and re-extracted with $3 \mathrm{~mL}$ of hexane and $3 \mathrm{~mL}$ of $0.9 \%$ $\mathrm{NaCl}$ solution. The organic phase (acyl methyl estered fatty acids) was used for GC analysis. Soxhlet-based extraction method was applied to determine seed oil content with petroleum ether as the organic solvent in 2012 based on a seed dry weight. Briefly, seeds were ground into powder by a pulverizer (Wenlin Dalin Machine Com. Ltd, China). Five to six grams of sample were dried at $100^{\circ} \mathrm{C}$ for $4 \mathrm{~h}$. Weight of dried samples were recorded and extracted by ethyl ether absolute for $24 \mathrm{~h}$ with a reflux condensation device. A low boiling point (lower than $60^{\circ} \mathrm{C}$ ) extraction solvent ethyl ether was used to avoid direct extraction of membrane-bound lipids. The crude lipids were composed of free lipids in the seed. For the experiments in 2010 and 2011, fatty acids were used to stand for "seed oil content". It was previously reported that there was strong correlation between fatty acids and seed oil content in the model plant Arabidopsis- a close relative to Brassica napus L. (Hobbs et al. 2004). In 2012, seed oil content was defined as crude lipids from canola seeds.

\section{Transmission electron microscopy (TEM)}

Siliques and seeds were sampled from the main inflorescence of HOCL and LOCL of plants at 30, 40, and 50 DAA. In order to minimize sampling difference, the samples were taken at the same position of the main inflorescence of plants with very similar growth and height. Siliques of the two lines were cut into $0.5 \times 0.5 \mathrm{~cm}$ small pieces and the middle portions were used. Seeds of the two lines were evenly cut into two parts along the axis of cotyledons. The procedure for the TEM technique was the same to the description by Chen et al. (2012). Briefly, the samples were fixed with $2.5 \%$ gluteraldehyde in sodium phosphate buffer, postfixed in osmium tetroxide, dehydrated, and embedded in Spurr's resin. Transverse ultrathin sections were observed under a TEM (JEM-1230, JEOL, Japan).

Silique fresh and dry weight and chlorophyll determination Immature seeds were carefully detached from developing siliques and both were weighed immediately for fresh weight in 2010 and 2011. Since fresh weight-based carbohydrate measurement is usually affected by variable high water content in seeds, an absolute content of carbohydrate was also performed as on a seed dry weight basis. Therefore, in 2012, immature separated seeds and siliques were heated at $105^{\circ} \mathrm{C}$ for $30 \mathrm{~min}$ and were then dried at $70^{\circ} \mathrm{C}$ to a constant dry weight. Separated siliques in the consecutive three years were ground into fine powder with liquid nitrogen and extracted by $800 \mathrm{~mL} \mathrm{~L}^{-1}$ of acetone. The total chlorophyll content was estimated as described by Lichtenthaler (1987).

\section{Carbohydrate content measurement}

To determine the dynamic changes of carbohydrates, fresh immature siliques and seeds from 2010 and 2011 seasons were ground into powder in liquid nitrogen while dried immature siliques and seeds were ground into powder by a pulverizer. About $100 \mathrm{mg}$ powder was boiled twice in $10 \mathrm{~mL}$ of $800 \mathrm{~mL} \mathrm{~L}^{-1}$ ethanol for $30 \mathrm{~min}$ and centrifuged at $10000 \times g$ after the extract was cooled down to room temperature. One hundred milligrams of activated charcoal was added to the supernatant to remove chlorophyll. The chlorophyll-free supernatant was then used for determination of glucose, fructose, and sucrose according to Hendrix (1993). The starch in the pellets was digested with amyloglucosidase for $100 \mathrm{~min}$ at $55^{\circ} \mathrm{C}$ and determined according to Hendrix (1993). The remaining sediment was used to estimate cellulose content. The pellets were digested in an acetic-nitric reagent and the cellulose content was determined by anthrone according to the method described by Updegraff (1969).

\section{Statistical analysis}

Means of all the physiological traits of two lines were compared using Duncan's test at $\mathrm{P}<0.05$ at each developmental stage in 2010, 2011, and 2012. Correlation analysis between fatty acid content (lipid content) and each physiological indexes, namely, silique and seed weight, silique chlorophyll content, silique and seed fructose content, silique and seed glucose content, silique and seed sucrose content, silique and seed starch content, and silique and seed cellulose content, respectively, was performed during whole seed development. Factor analysis was also performed using these physiological parameters for dimension reduction. These analyses were performed using SPSS software.

\section{Results}

Dynamics of fresh and dry weight in developing silique and seed of HOCL and LOCL

\section{Silique fresh and dry weight}

After fertilization, siliques developed very quickly from 10 to 30 DAA in both canola lines with a near-linear increment in each year (Figure 1A). Around 79\% and $88 \%$ in $\mathrm{HOCL}$ and $91 \%$ and $79 \%$ in LOCL of silique fresh matter was produced before 30 DAA in 2010 and 2011, respectively. From 10 to 30 DAA, silique fresh weight 

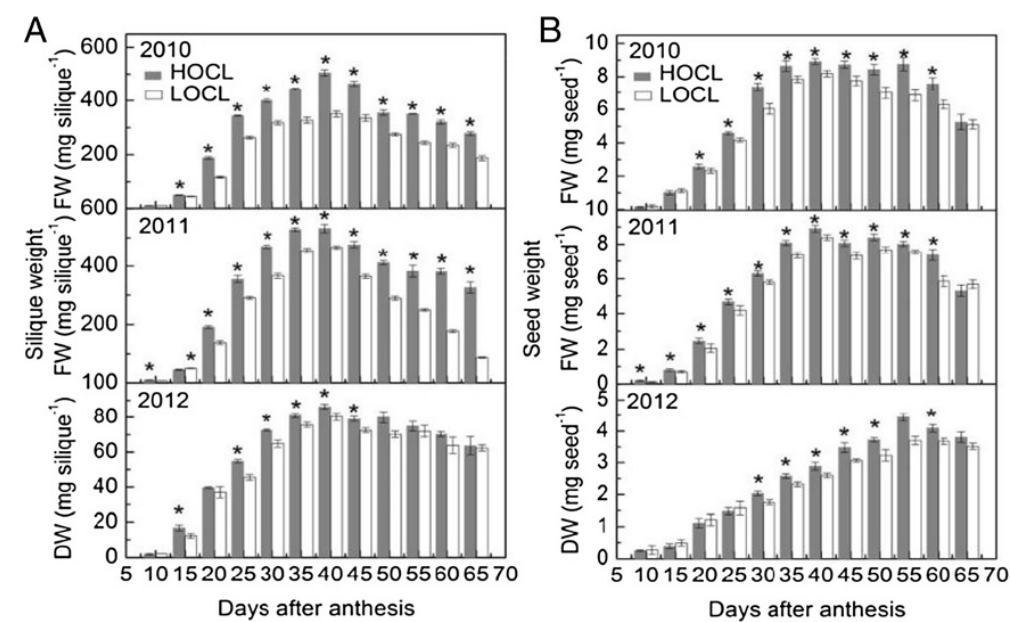

Figure 1 Dynamic of silique fresh weight in 2010, 2011, and dry weight in 2012 (A) and seed fresh weight in 2010, 2011, and dry weight in 2012 (B) of canola high oil content line (HOCL) and low oil content line (LOCL) from 10 to 65 days after anthesis (DAA) at a 5-day interval. Each value is the mean of 15 main-inflorescence siliques of five plants from each of three replicate plots. Error bars represent standard errors. "**" at each developmental stage indicates a significant difference at 5\% probability between HOCL and LOCL in both years.

increased with an average of 19.6 and $22.9 \mathrm{mg} \mathrm{day}^{-1}$ in HOCL in 2010 and 2011, respectively, which were much higher than those in LOCL (15.4 and $17.9 \mathrm{mg}^{\text {day }^{-1}}$ ). From 30 to 40 DAA, growth rate of silique in both lines was much smaller than that of the previous stages. There was significant difference of silique fresh weight between two lines. Notably, compared with LOCL, HOCL produced more fresh matters than the LOCL from 20 DAA onwards, yielding more fresh matter by $44 \%$ and $14 \%$ at 40 DAA in 2010 and 2011, respectively. Silique dry weight also accumulated with high speed and produced $84 \%$ and $89 \%$ of total dry matter before 30 DAA in both lines, which indicated an average of 2.4 and $2.1 \mathrm{mg}$ day $^{-1}$ of growth rate in HOCL and LOCL (Figure 1A). Decrease of silique dry weight occurred from 40 DAA in both HOCL and LOCL. Significantly higher silique dry weight was found in HOCL mainly from 15 to 50 DAA with an increment up to $9.8 \mathrm{mg} \mathrm{day}^{-1}$ of growth rate as a comparison with LOCL (Figure 1A).

\section{Seed fresh and dry weight}

Generally, similar near-linear increments of fresh and dry weight in both HOCL and LOCL were observed in developing seeds in comparison to developing siliques from 10 to $30 \mathrm{DAA}$, but this trend was extended to 40 DAA in 2010 and 2011, and 55 DAA in 2012, respectively (Figure $1 \mathrm{~B})$. The average seed growth rate reached $0.29 \mathrm{mg} \mathrm{day}^{-1}$ in HOCL for both years and at 0.25 and $0.27 \mathrm{mg} \mathrm{day}^{-1}$ in LOCL in 2010 and 2011, respectively. Seed fresh weight then underwent a steady period with a relatively higher and stable weight for 2 weeks in HOCL and LOCL from 40 to 55 DAA in two years (Figure 1B) and, thereafter, decreased due to dehydration at seed maturation stage. Marked difference of seed fresh weight between HOCL and LOCL was found from 20 to 55 DAA. Although seed fresh weight peaked at 40 DAA for both HOCL and LOCL, the biggest gap of seed fresh weight was at 55 and 60 DAA, which showed a faster decrease of $22 \%$ and $21 \%$ in LOCL in comparison with HOCL in 2010 and 2011 (Figure 1B). Different from seed fresh weight, seed dry weight kept increasing from 10 to 55 DAA in both lines and reduced from 55 DAA, which was much more in accordance with seed fresh weight in 2010 and 2011 (Figure 1B). Seed dry weight of LOCL was $83.3 \%$ of HOCL at 55 DAA (Figure 1B). Therefore, seed physiological maturation commenced from 55 DAA for both HOCL and LOCL (Figure 1B).

Taken together, HOCL exhibited significantly higher silique and seed fresh and dry weight, indicating a higher potential to produce higher seed oil content.

\section{Dynamic of seed oil content in HOCL and LOCL}

Seed oil content in the three consecutive growth seasons was monitored from 10 to 60 DAA (Figure 2). Before 30 DAA, oil content was only a small proportion of seed fresh weight in both lines indicating other metabolites such as carbohydrates (Figures 3, 4, 5, 6, 7) but not lipids depositing in the liquid endosperm in 2010 and 2011. Along with the increasing seed weight (Figure 1B), oil content rose dramatically before 55 DAA in 2010 and 2011 (Figure 2). Although the difference of oil content between HOCL and LOCL at early seed developing stage was statistically significant, this gap of oil content became significantly larger after 45 DAA in 2010 and 2011 (Figure 2). Compared to LOCL, the maximum oil 


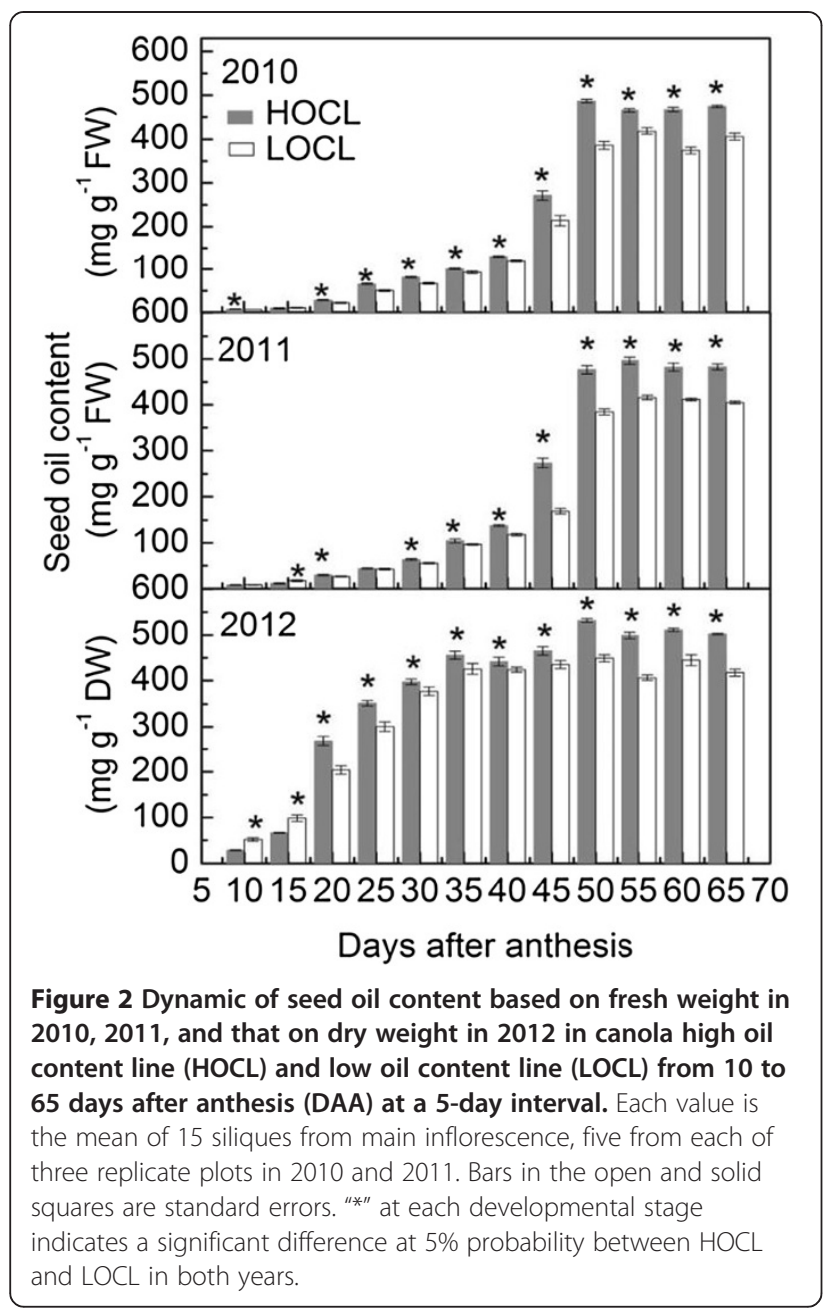

content of HOCL were 16\% and 19\% higher in 2010 and 2011, respectively (Figure 2). Similarly, lipids content on a dry weight basis accumulated in developing seed with high speed from 20 to 50 DAA without much difference between two lines. HOCL showed constantly 16\% more lipid content than LOCL after 50 DAA in a dry weight basis. A common property worth noting in fatty acid/lipids content during seed development was that the highest amount was not at the full maturation stage at 65 DAA but at the beginning of seed dehydration at 50 DAA (Figure 2).

\section{TEM of silique and seed in HOCL and LOCL}

The significant difference between HOCL and LOCL of seed oil content during seed development led us to compare their silique and seed ultrastructure at 30, 40, and 50 DAA (Figure 3) representing three seed oil formation stages, namely, early, middle, and late stages, respectively. At 30 DAA, seed cells were mainly composed of nucleolus, large vacuoles, chloroplasts, and oil bodies. Chloroplast was almost round in shape and filled with developing starch granule. HOCL contained more numbers of chloroplasts (6.7 per cell) than that of LOCL (5.5 per cell) (Figure 3A). Different from seed cell, silique cell mainly consisted of nucleolus, vacuoles, and chloroplasts without oil bodies. Furthermore, silique chloroplast appeared in oval shape and with relatively small proportion of matured starch granule (Figure 3A). At 40 DAA, large amount of proteins accumulated in seed cells of LOCL but oil bodies were more predominate in seed cells of HOCL. Furthermore, more chloroplasts were also found in HOCL (4.6 per cell) than that in LOCL (3.2 per cell). Unlike at previous stages, it was found that single silique cell was mainly occupied by a large vacuole merged from many small ones and chloroplasts were pushed near the cellular membrane. There was no difference between two lines except the number of chloroplast in silique cell (Figure 3B). Averagely, HOCL contained 17.6 chloroplasts per cell while LOCL contain 13.2 ones. Furthermore, starch grain in the chloroplast of seed cell matured (Figure 3B) at 50 DAA, a similar ultrastructure was observed in comparison with that at 40 DAA (Figure 3C). Thus, it was clear that 1.) seed cell in HOCL contained more chloroplasts, oil bodies and less proteins while the reverse result in LOCL; 2.) silique cell in HOCL had more chloroplasts than that in LOCL at developmental stages.

Dynamic of silique chlorophyll content in HOCL and LOCL Overall, chlorophyll content in silique kept on decreasing in both HOCL and LOCL in 2010, 2011, and 2012 (Figure 4). Silique chlorophyll content in HOCL was significantly higher than that in LOCL at most developmental stages. Silique chlorophyll contents in HOCL, averaged from 10 to $30 \mathrm{DAA}$, were $28 \% 31 \%$, and $31 \%$ higher than those of LOCL in 2010, 2011, and 2012, respectively (Figure 4). Those results along with a higher abundance of chloroplasts in silique cells of HOCL lead to our assumption that a higher photosynthetic production of carbohydrates in HOCL.

\section{Dynamics of silique and seed carbohydrate content in $\mathrm{HOCL}$ and LOCL \\ Fructose content}

Fructose belongs to hexose and is involved in many physiological metabolisms (Mccutchan and Monson 2001). Silique fructose content was significantly higher in HOCL than that of LOCL at 20 to 40 DAA while no difference after 40 DAA between two lines across three years (Figure 5A), indicating 20 to 40 DAA was the key stage for the differentiation of silique fructose metabolism between HOCL and LOCL. Silique fructose content in HOCL and LOCL declined to near zero level after 40 DAA suggesting that it was mostly converted in silique or transported into seed. Silique fructose content of HOCL were, in average, $48 \%$ and $57 \%$ higher than that 
Figure 3 Ultrastructure of silique (right panel) and seed (left panel) at 30 (A), 40 (B), and 50 (C) DAA by transmission electron microscopy (TEM). The circle in (A) is a magnification of chloroplast in the seed and silique. Cp, chloroplast; ImS, immature starch grain; MS, matured starch grain; $\mathrm{N}$, nucleolus; $\mathrm{O}$, oil body; $P$, protein; $V$, vacuole. Images are one representative out of 10 captured in 2012.

of LOCL in 2010 and 2011 based on fresh weight and was $48 \%$ higher than that of LCOL in 2012 on a dry weight basis from 20 to 40 DAA (Figure 5A).

Fructose content in developing seeds illustrated a very similar kinetic trend in both lines from 2010 to 2012 (Figure 5B). HOCL and LOCL showed a large increase of fructose content, peaked at $20 \mathrm{DAA}$ and then dropped rapidly close to zero. For the three years, peak seed fructose content in LOCL was only $77.5 \%, 78.8 \%$, and $79.3 \%$ of those of HOCL. However, there was little difference in seed fructose content between two lines after 40 DAA over three years.

\section{B}
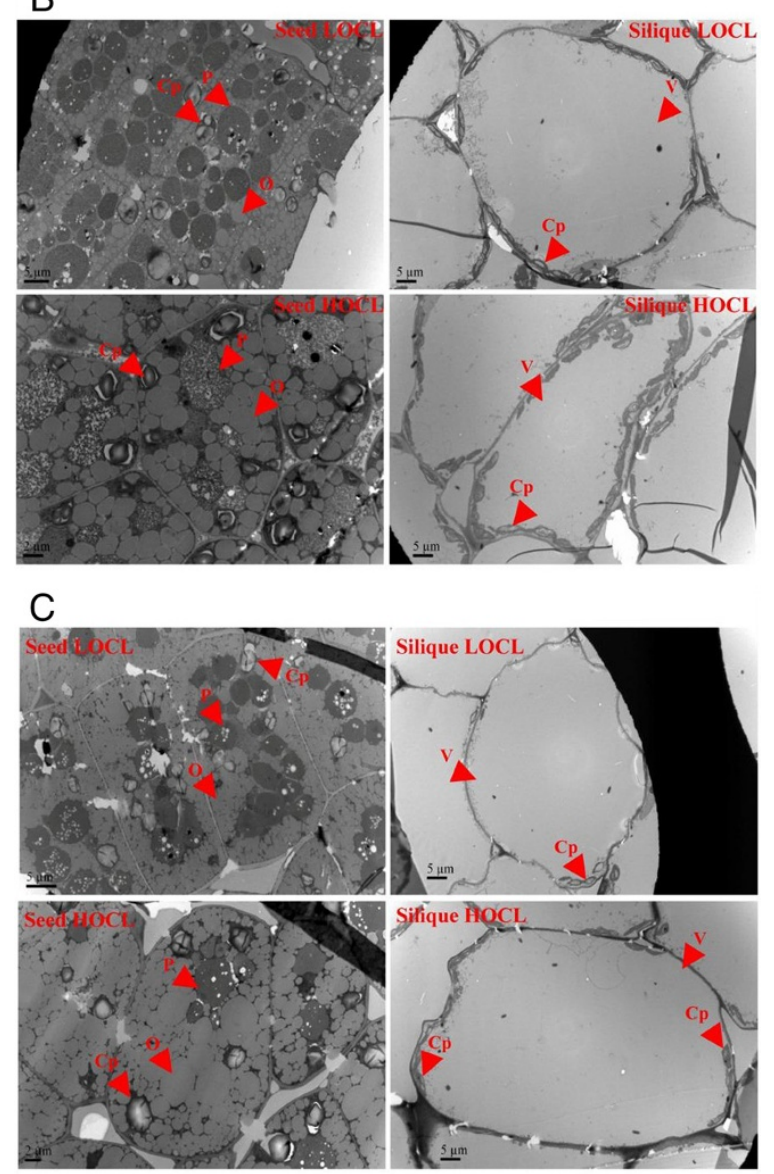

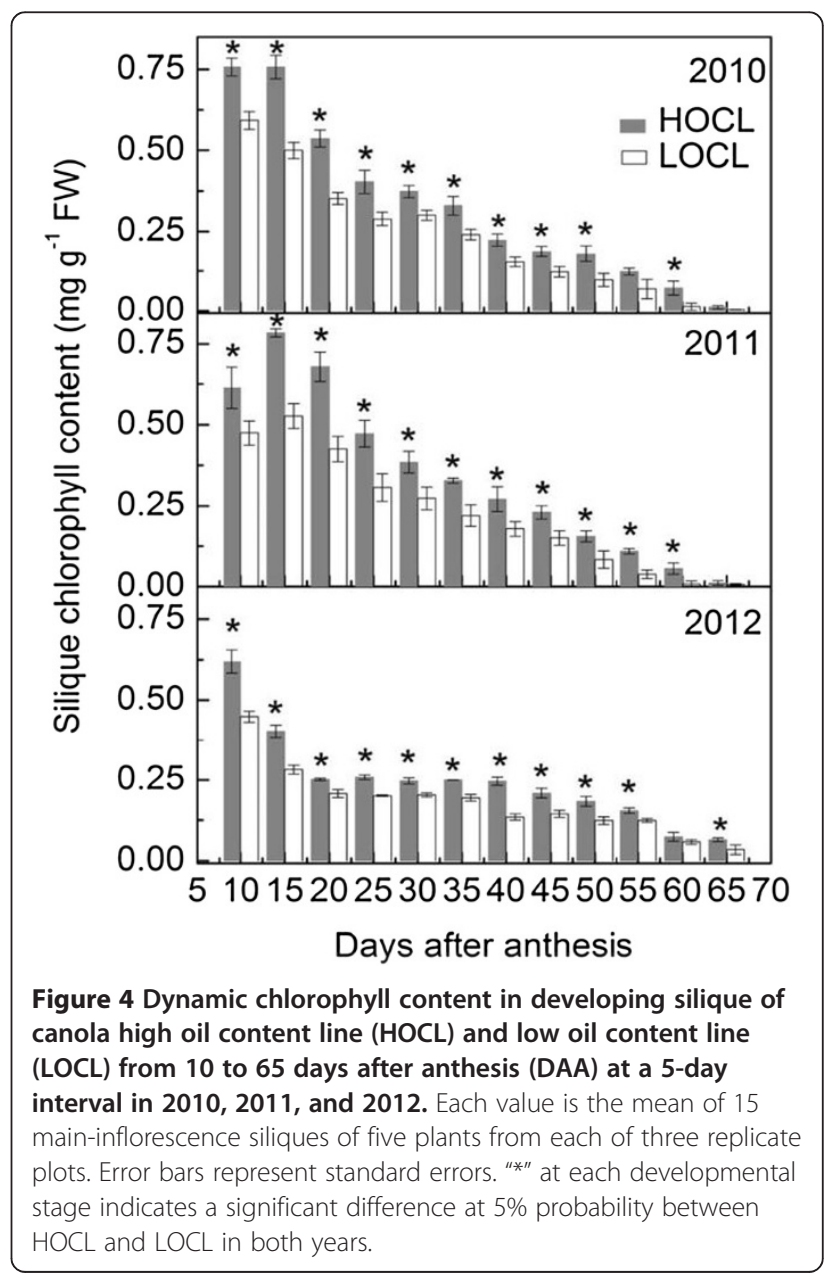



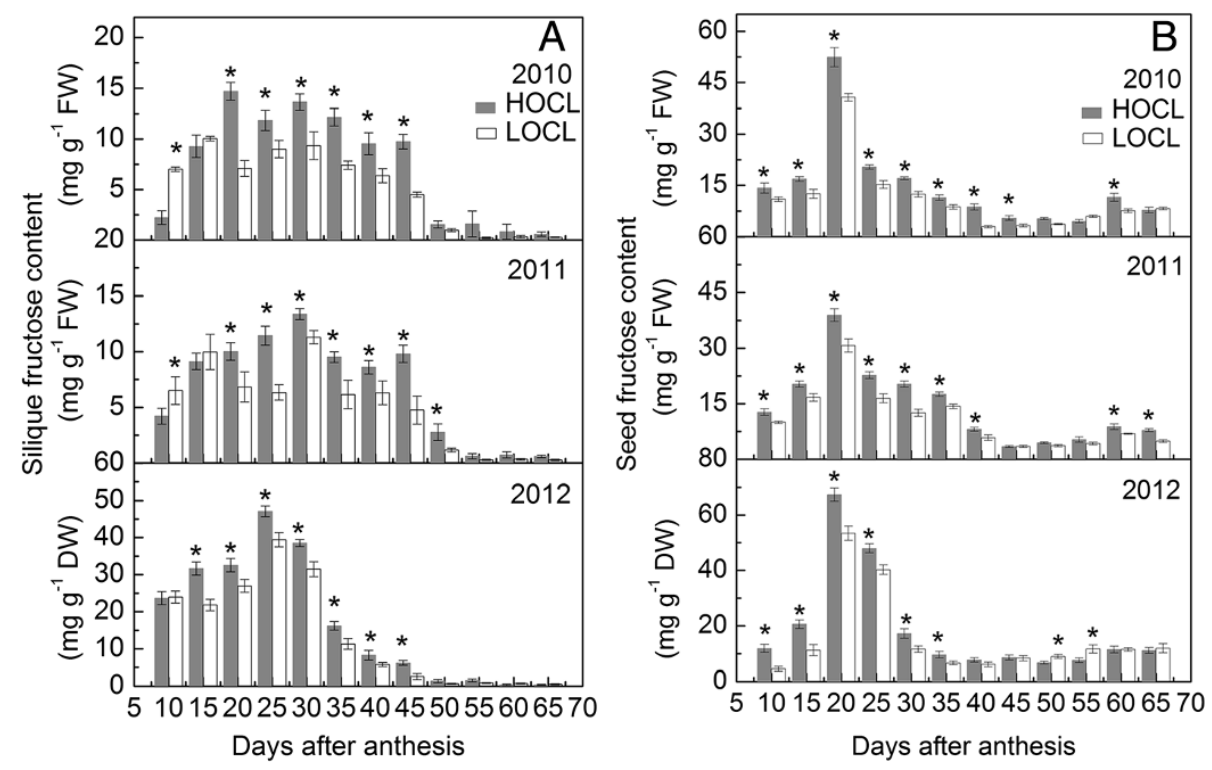

Figure 5 Dynamic of silique fructose content based on fresh weight in 2010, 2011, and that on dry weight in 2012 (A) and seed fructose content based on fresh weight in 2010, 2011, and that on dry weight in 2012 (B) of canola high oil content line (HOCL) and low oil content line (LOCL) from 10 to 65 days after anthesis (DAA) at a 5-day interval. Each value is the mean of 15 siliques from main inflorescence, five from each of three replicate plots. Bars in the open and solid squares are standard errors. "*" at each developmental stage indicates a significant difference at $5 \%$ probability between HOCL and LOCL in both years.

\section{Glucose content}

Similar to the trend of fructose content in developing siliques was observed for glucose content (Figure 6A). From 20 to 45 DAA, HOCL showed significantly higher glucose content than that of LOCL. The maximum glucose content in developing siliques of HOCL was found at 25 DAA of 2010 and 2012 and at 30 DAA of 2011, which synthesized $47.5 \%, 16.5 \%$, and $23.4 \%$ more silique glucose as compared with LOCL. The glucose content dropped to very low level from 50 DAA indicating an active stage from 20 to 45 DAA of glucose metabolism (Figure 6A).

In general, glucose content in developing seed varied similar to the seed fructose content (Figures 5B, 6B). We found that seed glucose content accumulated rapidly before $25 \mathrm{DAA}$ and then declined dramatically in both
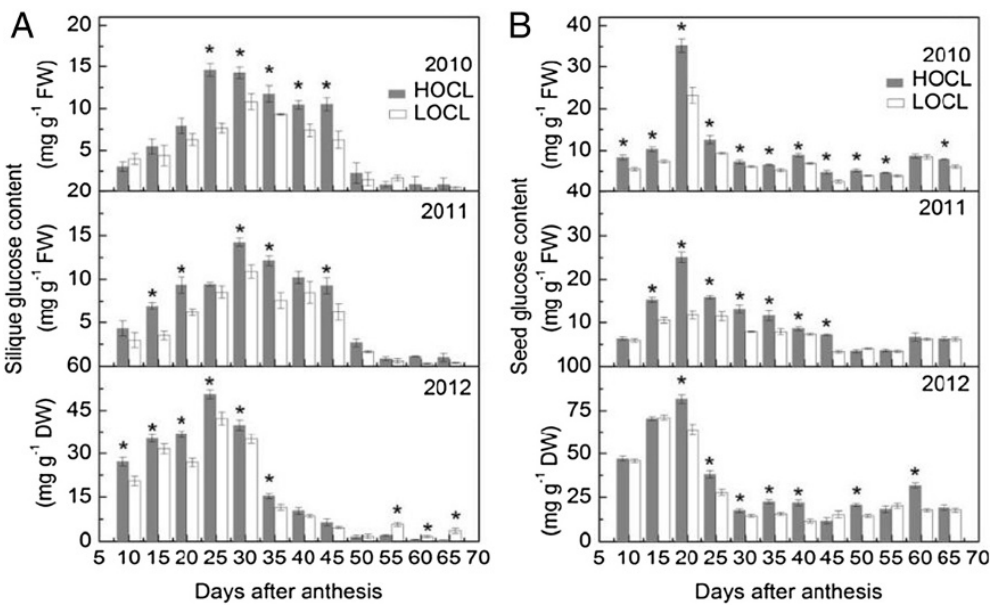

Figure 6 Dynamic of silique glucose content based on fresh weight in 2010, 2011, and that on dry weight in 2012 (A) and seed glucose content based on fresh weight in 2010, 2011, and that on dry weight in 2012 (B) of canola high oil content line (HOCL) and low oil content line (LOCL) from 10 to 65 days after anthesis (DAA) at a 5-day interval. Each value is the mean of 15 siliques from main inflorescence, five from each of three replicate plots. Bars in the open and solid squares are standard errors. " "*" at each developmental stage indicates a significant difference at $5 \%$ probability between $\mathrm{HOCL}$ and LOCL in both years. 

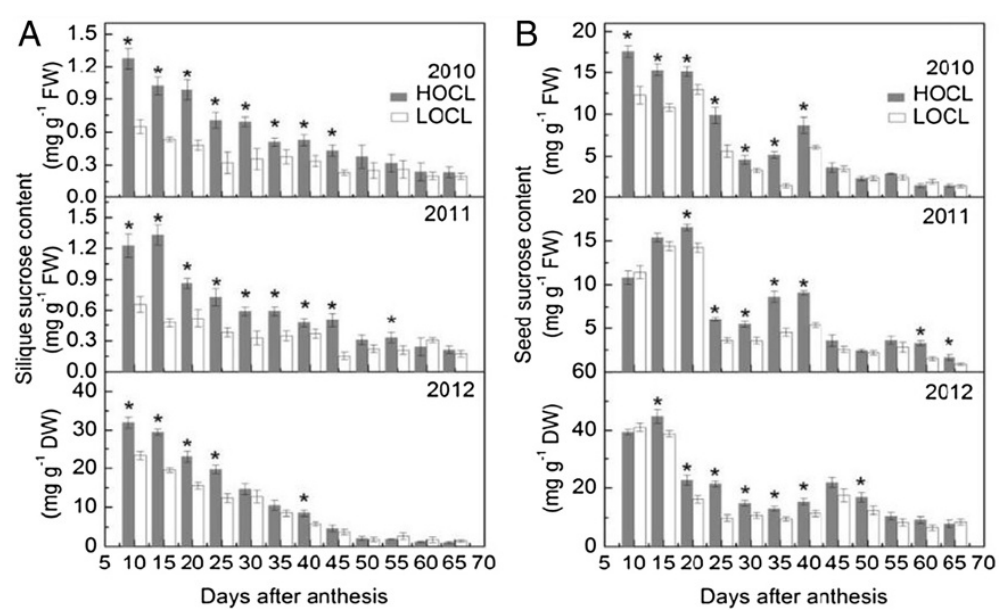

Figure 7 Dynamic of silique sucrose content based on fresh weight in 2010, 2011, and that on dry weight in 2012 (A) and seed sucrose content based on fresh weight in 2010, 2011, and that on dry weight in 2012 (B) of canola high oil content line (HOCL) and low oil content line (LOCL) from 10 to 65 days after anthesis (DAA) at a 5-day interval. Each value is the mean of 15 siliques from main inflorescence, five from each of three replicate plots. Bars in the open and solid squares are standard errors. " "*" at each developmental stage indicates a significant difference at $5 \%$ probability between $\mathrm{HOCL}$ and LOCL in both years.

lines in three years. Slightly different from developing silique, seed glucose content exhibited a small recovery in two lines during seed maturation, which was especially obvious for HOCL at 60 DAA in 2012 (Figure 6B). Significant difference of glucose content between HOCL and LOCL mostly found from 15 to 45 DAA. HOCL reached its peak abundance of glucose content at 20 DAA over the three consecutive years, when seed glucose content in LOCL were only $65.9 \%, 46.5 \%$, and $78.1 \%$ of that in HOCL, respectively (Figure 6B).

\section{Sucrose content}

Sucrose is an essential photo-assimilate, cleaved into fructose and glucose by invertase and sucrose synthase (Fallahi et al. 2008). Overall, sucrose content in silique was constantly in decline over time in both HOCL and LOCL in three years (Figure 7A). The large difference of sucrose content in silique was at 10 to 30 DAA between two lines regardless of the fresh or dry basis, indicating most of the sillque sucrose was possibly cleaved during early flowering stage but not late flowering or seed filling stage (Figure 7A).

Twenty DAA was the turning point where higher seed sucrose content was found in both lines in 2010 and 2011 and it then reduced to relatively lower values. Interestingly, seed sucrose content exhibited a second peak around 35 to 45 DAA in two lines during seed maturation of each year (Figure 7B). The remarkable distinction of seed sucrose content in two lines was also mainly observed from 20 to 45 DAA. Similarly, high seed sucrose content at early stage (10 to 15 DAA) was also detected compared to the peaks of fructose and glucose in seeds (Figure 7B). On average, seed sucrose content in HOCL were 83\%, 60\%, and 54\% more abundant in comparison to that in LOCL from 20 to 40 DAA in 2010, 2011, and 2012, respectively (Figure 7B).

\section{Starch content}

Starch synthesized in both siliques and seeds is considered as one of the major carbon suppliers for fatty acid synthesis (Andriotis et al. 2010). Thus, we hypothesized that silique and seed starch content in HOCL is higher than those in LOCL. Different from the dynamic changes of silique glucose, fructose and sucrose content, starch content accumulated from early flowering stage, peaked at 35 to 45 DAA and decreased gradually over time in HOCL and LOCL across three seasons (Figure 8A). The silique starch content varied across three seasons. HOCL only showed significantly and consistently higher starch content from 40 DAA in 2010, but exhibited significantly higher silique starch content than that of LOCL across the whole 65 day period in both 2011 and 2012. For instance, in 2012, the silique starch content in HOCL and LOCL were both peaked at 35 DAA, but HOCL accumulated a $30.3 \%$ more starch content compared to LOCL (Figure 8A).

Seed starch content in two lines was much higher based on fresh weight than silique starch content (Figure 8A,B). Furthermore, seed starch content in both lines generally declined from 10 DAA onwards across three seasons with some fluctuations. For example, there was a short period of increase in seed starch content from 10 to 20 DAA in HOCL in 2011 (Figure 8B). Figure 8B also illustrated that starch content in developing seed in HOCL was significant higher than that in LOCL in the majority of developmental stages. Across the 12 measured seed developmental stages, average starch content in HOCL increased 43\%, 37\%, and 37\% more than that of LOCL in the consecutive three years (Figure 8B). 

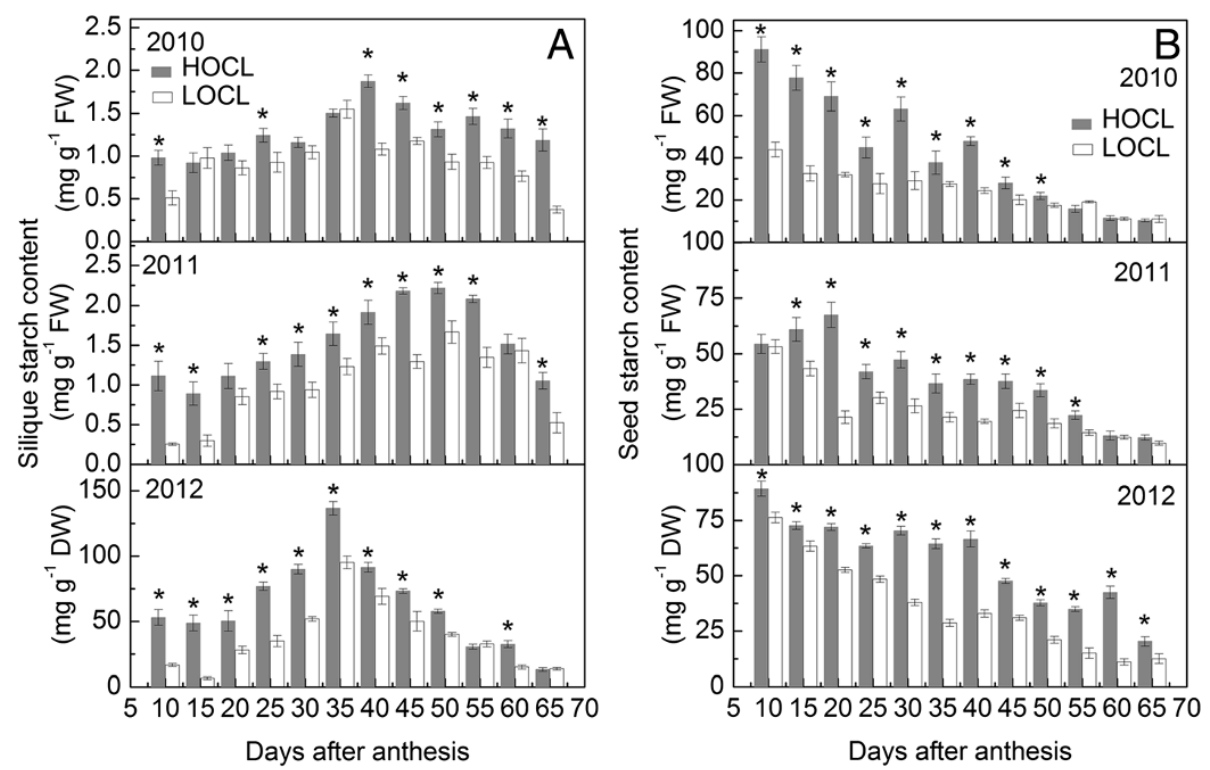

Figure 8 Dynamic of starch content based on fresh weight in 2010, 2011, and that on dry weight in 2012 (A) and seed starch content based on fresh weight in 2010, 2011, and that on 2012 (B) of canola high oil content line (HOCL) and low oil content line (LOCL) from 10 to 65 days after anthesis (DAA) at a 5-day interval. Each value is the mean of 15 siliques from main inflorescence, five from each of three replicate plots. Bars in the open and solid squares are standard errors. " "*" at each developmental stage indicates a significant difference at $5 \%$ probability between HOCL and LOCL in both years.

\section{Cellulose content}

Cellulose is the major component of plant cell wall, however, too much cellulose synthesized in siliques and seeds would consume excessive carbohydrates, which could have been used for synthesis of fatty acids (Louvet et al. 2011). Therefore, our hypothesis was that HOCL should synthesize less cellulose content than LOCL. We observed an overall increase of silique cellulose content across the growth stages, both in HOCL and LOCL, which was more pronounced from 55 DAA over three years (Figure 9A). However, HOCL showed distinctively less cellulose content than that in HOCL at the end of silique development. The largest difference of cellulose content between HOCL and LOCL was found at 65 DAA reaching 18.9 and $12.2 \mathrm{mg} \mathrm{g}^{-1}$ fresh weight in 2010 and 2011, respectively (Figure 9A). However, dry-weight based silique cellulose content of HOCL was significantly lower (21\%) than that of LOCL at 65 DAA (Figure 9A).
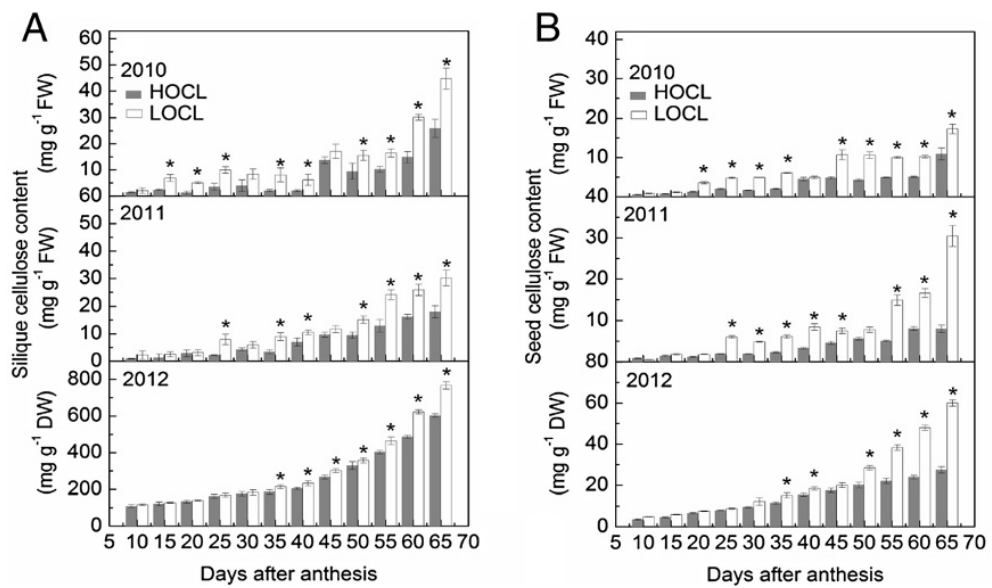

Figure 9 Dynamic of cellulose content based on fresh weight in 2010, 2011, and that on dry weight in 2012 (A) and seed cellulose content based on fresh weight in 2010, 2011, and that on dry weight in 2012 (B) of canola high oil content line (HOCL) and low oil content line (LOCL) from 10 to 65 days after anthesis (DAA) at a 5-day interval. Each value is the mean of 15 siliques from main inflorescence, five from each of three replicate plots. Bars in the open and solid squares are standard errors. "**" at each developmental stage indicates a significant difference at 5\% probability between $\mathrm{HOCL}$ and $\mathrm{LOCL}$ in both years. 
Similar deposition dynamics of cellulose in developing seed was observed in HOCL and LOCL over three years (Figure 9B). Significantly lower seed cellulose content in HOCL was found in contrast to LOCL from 35 to 65 DAA over three years. For instance, there was 37\%, 74\%, and $54 \%$ less seed cellulose content in HOCL in comparison with LCOL at 65 DAA in 2010, 2011, and 2012, respectively (Figure 9B).

\section{Correlation between seed oil content and physiological indexes and factor analysis}

The above results demonstrated that significant difference of physiological indexes exists between HOCL and LOCL during lipid biosynthesis. In order to understand how these factors were related and contributed to seed oil content during seed development, a correlation analysis between seed oil content and physiological indexes and factor analysis were performed using these physiological indexes. Tables 1, 2, and 3 showed that lipids were positively correlated with silique and seed weight except silique weight in LOCL in 2011. Seed lipids were very significantly associated with silique total chlorophyll in both lines under three experimental years. This indicated that decreasing silique chlorophyll content during seed development does not benefit seed oil accumulation. As for sugars, it was found that silique fructose, glucose, sucrose, and seed starch content were significantly and negatively correlated with lipids in both lines from 2010 to 2012. Generally, seed fructose, glucose, sucrose, and silique starch content showed similar correlations although some are not significant. This revealed that these physiological parameters were more environmentally dependent over three years. It was observed that silique and seed cellulose content was significantly related with lipids. The result illustrated that the more cellulose synthesized, the more adverse effect on seed lipids.

There were many physiological indexes and their contributions to seed oil accumulation may not be understood only based on the correlation analysis. We simplified the factors to reflect their contributions using factor analysis. All of these 13 physiological parameters could be explained by the first three factors, which were accounted for more than $90 \%$ of variance in both lines during three experimental seasons (Table 4). Thus, these three factors can be stand for the 14 physiological parameters when it came to the seed oil content during seed development.

In order to further reveal the distribution of these physiological parameters in these three groups, a rotate component matrix was listed in the Table 5. Factor 1, which accounted for $59 \% \sim 67 \%$ of the variation in different years of both lines, was strongly associated with total silique chlorophyll content, seed starch content, and silique and seed cellulose content. Factor 2, which accounted for $17 \% \sim 22 \%$ of the variation in different years of both lines, was mainly associated with silique and seed weight. Factor 3, which accounted for $7.5 \% \sim 10.5 \%$ of the variation in different years of both lines, was mainly correlated with seed fructose and glucose content. They could be regarded as carbohydrate source and polysaccharide factor, weight factor and seed hexose factor.

\section{Discussion}

The close relationship between silique and seed development in canola determines the crucial function of silique in canola seed yield and quality establishment (Zhang et al. 2011; Yang et al. 2012). For example, the capacity for seed numbers in a silique and the resistance for pod shattering during seed harvest have great impacts on seed yield (Wang et al. 2007b; Gan et al. 2008). Furthermore, silique is the sole tissue that directly connects with seed through funiculus, and thus it is easy to deduce that majority of nutrients in the seed from canola plants including synthesized by silique and other green tissues or by other senescent organs, i.e. leaves, should be transported from silique (Rossato et al. 2001; Dubousset et al. 2010). Although the importance of silique on canola seed reserve formation received great attentions, detailed mechanisms from physiological, biochemical, and molecular viewpoint is scarce. Recent evidence revealed that canola seed oil content was tightly associated with $B n R B C S 1 A$ expression levels and Rubisco activities in silique wall (Hua et al. 2012b). In another case, the expression of BnLEC1 in canola enhanced sucrose synthesis and transport in developing seed and silique contributed to the increase of seed oil content (Tan et al. 2011). Both highlighted the molecular regulation of seed oil synthesis by silique. In this investigation, we found some distinctive differences of silique and seed weight, chlorophyll content, major carbohydrate content between HOCL and LOCL derived from RIL population over three consecutive years. 1.) HOCL had significantly higher silique and seed weight than that of LOCL. 2.) HOCL produced markedly higher chlorophyll and sugar content in silique. 3.) Larger amount of proteins accumulated in developing seed cell of LOCL while considerable higher amount of oil bodies deposited in developing seed cell of HOCL. 4.) Correlation and factor analysis revealed that silique chlorophyll and seed starch content were the two most important positive factors while silique and seed cellulose content were the two major negative factors, affecting seed oil accumulation.

Before embryo differentiation and expansion, liquid endosperm in a closure of testa (or seed coat) occupies a developing seed (Johnson-Flanagan et al. 1992). During early seed developmental stage, demand for rapid seed swelling should be met to maximize a seed volume. Consequently, HOCL and LOCL both showed high-speed expansion before embryo became dominant in a seed at around 40 DAA. In our experiments, a large amount of 
Table 1 Correlation among the physiological traits and seed oil content in 2010 at seed developmental stages: the value in the upper triangle is the Person correlation coefficient in canola high oil content line (HOCL) while the lower triangle is that in canola low oil content line (LOCL)

\begin{tabular}{|c|c|c|c|c|c|c|c|c|c|c|c|c|c|c|}
\hline Parameters & $\begin{array}{l}\text { Seed oil } \\
\text { content }\end{array}$ & $\begin{array}{l}\text { Silique } \\
\text { weight }\end{array}$ & $\begin{array}{l}\text { Seed } \\
\text { weight }\end{array}$ & $\begin{array}{l}\text { Total } \\
\text { chlorophyll }\end{array}$ & $\begin{array}{l}\text { Silique } \\
\text { fructose }\end{array}$ & $\begin{array}{l}\text { Seed } \\
\text { fructose }\end{array}$ & $\begin{array}{l}\text { Silique } \\
\text { glucose }\end{array}$ & $\begin{array}{l}\text { Seed } \\
\text { glucose }\end{array}$ & $\begin{array}{l}\text { Silique } \\
\text { sucrose }\end{array}$ & $\begin{array}{l}\text { Seed } \\
\text { sucrose }\end{array}$ & $\begin{array}{l}\text { Silique } \\
\text { starch }\end{array}$ & $\begin{array}{l}\text { Seed } \\
\text { starch }\end{array}$ & $\begin{array}{l}\text { Silique } \\
\text { cellulose }\end{array}$ & $\begin{array}{l}\text { Seed } \\
\text { cellulose }\end{array}$ \\
\hline Seed oil content & 1 & 0.30 & 0.53 & $-0.86^{* *}$ & $-0.96^{* *}$ & -0.48 & $-0.74^{* *}$ & -0.38 & $-0.80^{* *}$ & $-0.72^{* *}$ & -0.27 & $-0.88^{* *}$ & $0.79^{* *}$ & $0.88^{* *}$ \\
\hline Silique weight & 0.33 & 1 & $0.94^{* *}$ & $-0.65^{* *}$ & -0.16 & -0.44 & 0.36 & -0.35 & $-0.71^{* *}$ & $-0.75^{* *}$ & $0.60^{* *}$ & -0.51 & 0.12 & 0.39 \\
\hline Seed weight & 0.56 & $0.93^{* *}$ & 1 & $-0.79 * *$ & -0.42 & -0.55 & 0.10 & -0.43 & $-0.78^{* *}$ & $-0.83^{* *}$ & 0.53 & $-0.66^{* *}$ & 0.28 & 0.55 \\
\hline Total chlorophyll & $-0.85^{* *}$ & $-0.72^{* *}$ & -0.81 & 1 & $0.79^{* *}$ & 0.42 & 0.41 & 0.26 & $0.96^{* *}$ & $0.83^{* *}$ & -0.01 & $0.96^{* *}$ & $-0.76^{* *}$ & $-0.88^{* *}$ \\
\hline Silique fructose & $-0.75^{* *}$ & 0.20 & -0.06 & 0.40 & 1 & 0.38 & $0.81^{* *}$ & 0.26 & $0.68^{* *}$ & 0.57 & 0.37 & $0.79^{* *}$ & $-0.75^{* *}$ & $-0.83^{* *}$ \\
\hline Seed fructose & -0.55 & -0.37 & -0.53 & 0.49 & $0.58^{*}$ & 1 & 0.22 & $0.94^{* *}$ & 0.45 & $0.64^{* *}$ & -0.12 & 0.41 & -0.30 & -0.40 \\
\hline Silique glucose & $-0.65^{* *}$ & 0.43 & 0.13 & 0.22 & $0.89^{* *}$ & 0.25 & 1 & 0.13 & 0.30 & 0.15 & $0.65^{* *}$ & 0.53 & $-0.65^{* *}$ & -0.55 \\
\hline Seed glucose & -0.42 & -0.33 & -0.47 & 0.37 & 0.47 & $0.97^{* *}$ & 0.13 & 1 & 0.31 & $0.58^{*}$ & -0.14 & 0.25 & -0.21 & -0.32 \\
\hline Silique sucrose & $-0.85^{* *}$ & $-0.71^{* *}$ & $-0.83^{* *}$ & $0.97^{* *}$ & 0.39 & 0.56 & 0.22 & 0.45 & 1 & $0.87^{* * *}$ & -0.06 & $0.94^{* *}$ & $-0.72^{* *}$ & $-0.86^{* *}$ \\
\hline Seed sucrose & $-0.82^{* *}$ & $-0.71^{* *}$ & $-0.84^{* *}$ & $0.93^{* *}$ & 0.36 & $0.59^{*}$ & 0.16 & 0.54 & $0.95^{* *}$ & 1 & -0.23 & $0.79^{* *}$ & $-0.61^{* *}$ & $-0.76^{* *}$ \\
\hline Silique starch & 0.30 & $0.86^{* *}$ & $0.83^{* *}$ & $-0.62^{* *}$ & 0.02 & -0.48 & 0.23 & -0.38 & $-0.60^{* *}$ & -0.51 & 1 & 0.08 & -0.47 & -0.25 \\
\hline Seed starch & $-0.90^{* *}$ & $-0.60^{* *}$ & $-0.73^{* *}$ & $0.95^{* *}$ & 0.48 & 0.52 & 0.33 & 0.39 & $0.97^{* *}$ & $0.91^{* *}$ & -0.51 & 1 & $-0.84^{* *}$ & $-0.90^{* *}$ \\
\hline Silique cellulose & $0.81^{* *}$ & 0.17 & 0.29 & $-0.74^{* *}$ & $-0.62^{* *}$ & -0.44 & -0.53 & -0.33 & $-0.72^{* *}$ & $-0.70^{* *}$ & 0.10 & $-0.77^{* *}$ & 1 & $0.90^{* *}$ \\
\hline Seed cellulose & $0.79^{* *}$ & 0.35 & 0.42 & $-0.83^{* *}$ & -0.57 & -0.47 & -0.45 & -0.31 & $-0.78^{* *}$ & $-0.70^{* *}$ & 0.34 & $-0.80^{* *}$ & 0.23 & 1 \\
\hline
\end{tabular}

*,**indicate two parameters are significant correlated at $\mathrm{P}<0.05$ and $\mathrm{P}<0.01$, respectively. 
Table 2 Correlation among the physiological traits and seed oil content in 2011 at seed developmental stages: the value in the upper triangle is the Person correlation coefficient in canola high oil content line (HOCL) while the lower triangle is that in canola low oil content line (LOCL)

\begin{tabular}{|c|c|c|c|c|c|c|c|c|c|c|c|c|c|c|}
\hline Parameters & $\begin{array}{l}\text { Seed oil } \\
\text { content }\end{array}$ & $\begin{array}{l}\text { Silique } \\
\text { weight }\end{array}$ & $\begin{array}{l}\text { Seed } \\
\text { weight }\end{array}$ & $\begin{array}{l}\text { Total } \\
\text { chlorophyll }\end{array}$ & $\begin{array}{l}\text { Silique } \\
\text { fructose }\end{array}$ & $\begin{array}{l}\begin{array}{l}\text { Seed } \\
\text { fructose }\end{array} \\
\end{array}$ & $\begin{array}{l}\text { Silique } \\
\text { glucose }\end{array}$ & $\begin{array}{l}\text { Seed } \\
\text { glucose }\end{array}$ & $\begin{array}{l}\text { Silique } \\
\text { sucrose }\end{array}$ & $\begin{array}{l}\text { Seed } \\
\text { sucrose }\end{array}$ & $\begin{array}{l}\text { Silique } \\
\text { starch }\end{array}$ & $\begin{array}{l}\text { Seed } \\
\text { starch }\end{array}$ & $\begin{array}{l}\begin{array}{l}\text { Silique } \\
\text { cellulose }\end{array} \\
\end{array}$ & $\begin{array}{l}\text { Seed } \\
\text { cellulose }\end{array}$ \\
\hline Seed oil content & 1 & -0.01 & 0.57 & $-0.88^{* *}$ & $-0.91^{* *}$ & $-0.66^{* *}$ & $-0.73^{* *}$ & $-0.67^{* *}$ & $-0.73^{* *}$ & $-0.69^{* *}$ & 0.49 & $-0.73^{* *}$ & $0.94^{* *}$ & $0.80^{* *}$ \\
\hline Silique weight & 0.35 & 1 & $0.80^{* *}$ & -0.35 & 0.10 & -0.22 & $0.61^{* *}$ & -0.15 & -0.44 & -0.50 & $0.73^{* *}$ & -0.39 & -0.02 & -0.08 \\
\hline Seed weight & $0.58^{*}$ & 0.94 & 1 & $-0.82^{* *}$ & -0.45 & $-0.60^{* *}$ & 0.07 & -0.55 & $-0.81^{* *}$ & $-0.81^{* *}$ & $0.86^{* *}$ & $-0.76^{* *}$ & 0.54 & 0.43 \\
\hline Total chlorophyll & $-0.88^{* *}$ & -0.67 & $-0.79^{* *}$ & 1 & $0.81^{* *}$ & $0.70^{* *}$ & 0.39 & $0.66^{* *}$ & $0.85^{* *}$ & $0.89^{* *}$ & $-0.67^{* *}$ & $0.85^{* *}$ & $-0.90^{* *}$ & $-0.80^{* *}$ \\
\hline Silique fructose & $-0.81^{* *}$ & 0.13 & -0.14 & $0.60^{* *}$ & 1 & 0.56 & $0.77^{* *}$ & $0.61^{* *}$ & 0.57 & $0.59^{*}$ & -0.43 & $0.64^{* *}$ & $-0.87^{* *}$ & $-0.73^{* *}$ \\
\hline Seed fructose & $-0.70^{* *}$ & -0.36 & -0.56 & $0.73^{* *}$ & $0.58^{*}$ & 1 & 0.39 & $0.87^{* *}$ & $0.63^{* *}$ & $0.72^{* *}$ & -0.40 & 0.28 & $-0.62^{* *}$ & -0.52 \\
\hline Silique glucose & $-0.75^{* *}$ & 0.30 & 0.02 & 0.46 & $0.95^{* *}$ & 0.50 & 1 & 0.48 & 0.20 & 0.11 & 0.04 & 0.20 & $-0.65^{* *}$ & -0.54 \\
\hline Seed glucose & $-0.70^{* *}$ & -0.27 & -0.46 & $0.72^{* *}$ & $0.69^{* *}$ & $0.96^{* *}$ & $0.58^{*}$ & 1 & $0.58^{*}$ & $0.58^{*}$ & -0.44 & 0.29 & -0.55 & -0.39 \\
\hline Silique sucrose & $-0.82^{* *}$ & -0.77 & $-0.85^{* *}$ & $0.95^{* *}$ & 0.44 & 0.54 & 0.31 & 0.51 & 1 & $0.84^{* *}$ & $-0.59^{*}$ & $0.76^{* *}$ & $-0.72^{* *}$ & $-0.66^{* *}$ \\
\hline Seed sucrose & $-0.78^{* *}$ & $-059^{*}$ & $-0.68^{* *}$ & $0.90^{* *}$ & 0.47 & $0.75^{* *}$ & 0.39 & $0.74^{* *}$ & $0.82^{* *}$ & 1 & $-0.61^{* *}$ & $0.68^{* *}$ & $-0.73^{* *}$ & $-0.66^{* *}$ \\
\hline Silique starch & 0.51 & $0.69^{* *}$ & $0.84^{* *}$ & $-0.59^{*}$ & -0.16 & $-0.63^{* *}$ & -0.06 & -0.57 & $-0.60^{* *}$ & -0.55 & 1 & $-0.66^{* *}$ & 0.36 & 0.13 \\
\hline Seed starch & $-0.86^{* *}$ & -0.51 & $-0.64^{* *}$ & $0.94^{* *}$ & $0.68^{* *}$ & $0.71^{* *}$ & $0.57^{*}$ & $0.72^{* *}$ & $0.85^{* *}$ & $0.86^{* *}$ & -0.39 & 1 & $-0.77^{* *}$ & -0.71 \\
\hline Silique cellulose & $0.93^{* *}$ & 0.37 & 0.53 & $-0.89 * *$ & $-0.74^{* *}$ & $-0.63^{* *}$ & $-0.67^{* *}$ & $-0.60^{* *}$ & $-0.83^{* *}$ & $-0.75^{* *}$ & 0.337 & $-0.89^{* *}$ & 1 & 0.94 \\
\hline Seed cellulose & $0.93^{* *}$ & 0.37 & 0.54 & $-0.89^{* *}$ & $-0.74 * *$ & $-0.66^{* *}$ & $-0.68^{* *}$ & $-0.63^{* *}$ & $-0.82^{* *}$ & $-0.77^{* *}$ & 0.34 & $-0.91^{* *}$ & $0.94^{* *}$ & 1 \\
\hline
\end{tabular}

****indicate two parameters are significant correlated at $\mathrm{P}<0.05$ and $\mathrm{P}<0.01$, respectively. 
Table 3 Correlation among the physiological traits and seed oil content in 2012 at seed developmental stages: the value in the upper triangle is the Person correlation coefficient in canola high oil content line (HOCL) while the lower triangle is that in canola low oil content line (LOCL)

\begin{tabular}{|c|c|c|c|c|c|c|c|c|c|c|c|c|c|c|}
\hline Parameters & $\begin{array}{l}\text { Seed oil } \\
\text { content }\end{array}$ & $\begin{array}{l}\text { Silique } \\
\text { weight }\end{array}$ & $\begin{array}{l}\text { Seed } \\
\text { weight }\end{array}$ & $\begin{array}{l}\text { Total } \\
\text { chlorophyll }\end{array}$ & $\begin{array}{l}\text { Silique } \\
\text { fructose }\end{array}$ & $\begin{array}{l}\begin{array}{l}\text { Seed } \\
\text { fructose }\end{array} \\
\end{array}$ & $\begin{array}{l}\text { Silique } \\
\text { glucose }\end{array}$ & $\begin{array}{l}\text { Seed } \\
\text { glucose }\end{array}$ & $\begin{array}{l}\text { Silique } \\
\text { sucrose }\end{array}$ & $\begin{array}{l}\text { Seed } \\
\text { sucrose }\end{array}$ & $\begin{array}{l}\text { Silique } \\
\text { starch }\end{array}$ & $\begin{array}{l}\text { Seed } \\
\text { starch }\end{array}$ & $\begin{array}{l}\begin{array}{l}\text { Silique } \\
\text { cellulose }\end{array} \\
\end{array}$ & $\begin{array}{l}\text { Seed } \\
\text { cellulose }\end{array}$ \\
\hline Seed oil content & 1 & $0.97^{* *}$ & $0.90^{* *}$ & $-0.86^{* *}$ & $-0.62^{* *}$ & -0.25 & $-0.60^{* *}$ & $-0.88^{* *}$ & $-0.93^{* *}$ & -0.56 & 0.50 & $-0.92^{* *}$ & $0.58^{*}$ & $0.62^{* *}$ \\
\hline Silique weight & $0.94^{* *}$ & 1 & $0.83^{* *}$ & $-0.80^{* *}$ & -0.57 & -0.22 & -0.55 & $-0.85^{* *}$ & $-0.87^{* *}$ & $-0.65^{* *}$ & 0.63 & $-0.85^{* *}$ & 0.44 & 0.49 \\
\hline Seed weight & $0.92^{* *}$ & $0.81^{* *}$ & 1 & $-0.89 * *$ & $-0.81^{*}$ & -0.28 & $-0.78^{* *}$ & $-0.76^{* *}$ & $-0.98^{* *}$ & -0.21 & 0.17 & $-0.97^{* *}$ & $0.81^{* *}$ & $0.84^{* *}$ \\
\hline Total chlorophyll & $-0.89^{* *}$ & $-0.77^{* *}$ & $-0.84^{* *}$ & 1 & $0.62^{* *}$ & 0.01 & 0.56 & $0.60^{* *}$ & $0.92^{* *}$ & 0.35 & -0.11 & $0.92^{* *}$ & $-0.77^{* *}$ & $-0.79^{* *}$ \\
\hline Silique fructose & $-0.60^{* *}$ & -0.48 & $-0.81^{* *}$ & 0.51 & 1 & 0.56 & $0.97^{* *}$ & 0.50 & $0.79^{* *}$ & -0.19 & -0.07 & $0.74^{* *}$ & $-0.71^{* *}$ & $-0.74^{* *}$ \\
\hline Seed fructose & -0.32 & -0.35 & -0.52 & 0.10 & $0.68^{* *}$ & 1 & 0.53 & 0.46 & 0.25 & -0.31 & -0.19 & 0.25 & -0.24 & -0.27 \\
\hline Silique glucose & $-0.63^{* *}$ & -0.52 & $-0.83^{* *}$ & 0.53 & $0.99^{* *}$ & $0.70^{* *}$ & 1 & 0.53 & $0.76^{* *}$ & -0.15 & -0.11 & $0.71^{* *}$ & $-0.68^{* *}$ & $-0.71^{* *}$ \\
\hline Seed glucose & $-0.74^{* *}$ & $-0.76^{* *}$ & $-0.74^{* *}$ & 0.47 & 0.54 & $0.72^{* *}$ & $0.57^{*}$ & 1 & $0.77^{* *}$ & 0.48 & -0.53 & $0.75^{* *}$ & -0.479 & -0.515 \\
\hline Silique sucrose & $-0.95^{* *}$ & $-0.86^{* *}$ & $-0.98^{* *}$ & $0.87^{* *}$ & $0.78^{* *}$ & 0.49 & $0.81^{* *}$ & $0.76^{* *}$ & 1 & 0.29 & -0.22 & $0.96^{* *}$ & $-0.77^{* *}$ & $-0.80^{* *}$ \\
\hline Seed sucrose & $-0.77^{* *}$ & $-0.87^{* *}$ & -0.54 & 0.56 & 0.15 & 0.04 & 0.19 & $0.58^{*}$ & $0.59^{*}$ & 1 & $-0.76^{* *}$ & 0.276 & 0.19 & 0.16 \\
\hline Silique starch & 0.04 & 0.31 & -0.21 & 0.21 & 0.33 & -0.03 & 0.29 & -0.20 & 0.13 & -0.52 & 1 & -0.21 & -0.28 & -0.23 \\
\hline Seed starch & $-0.78^{* *}$ & $-0.58^{*}$ & $-0.88^{* *}$ & $0.84^{* *}$ & $0.72^{* *}$ & 0.35 & $0.73^{* *}$ & 0.55 & $0.87^{* *}$ & 0.25 & 0.482 & 1 & $-0.81^{* *}$ & $-0.84^{* *}$ \\
\hline Silique cellulose & $0.68^{* *}$ & 0.44 & $0.82^{* *}$ & $-0.77^{* *}$ & $-0.75^{* *}$ & -0.40 & $-0.76^{* *}$ & -0.49 & $-0.80^{* *}$ & -0.12 & $-0.59^{*}$ & $-0.92^{* *}$ & 1 & $0.99^{* *}$ \\
\hline Seed cellulose & $0.83^{* *}$ & $0.66^{* *}$ & $0.94^{* *}$ & $-0.83^{* *}$ & $-0.84^{* *}$ & -0.50 & $-0.86^{* *}$ & $-0.65^{* *}$ & $-0.94^{* *}$ & -0.33 & -0.42 & $-0.94 * *$ & $0.94^{* *}$ & 1 \\
\hline
\end{tabular}

****indicate two parameters are significant correlated at $\mathrm{P}<0.05$ and $\mathrm{P}<0.01$, respectively. 
Table 4 Total variance explained for each factor based on 14 physiological indexes of canola high oil content line (HOCL) and low oil content line (LOCL) from 2010 to 2012

\begin{tabular}{|c|c|c|c|c|c|c|c|c|c|c|c|c|}
\hline \multirow[t]{2}{*}{ Factors } & \multicolumn{2}{|c|}{ HOCL 2010} & \multicolumn{2}{|c|}{ LOCL 2010} & \multicolumn{2}{|c|}{ HOCL 2011} & \multicolumn{2}{|c|}{ LOCL 2011} & \multicolumn{2}{|c|}{ HOCL 2012} & \multicolumn{2}{|c|}{ LOCL 2012} \\
\hline & $\%$ of variance & Cumulative $\%$ & $\%$ of variance & Cumulative \% & $\%$ of variance & Cumulative \% & $\%$ of variance & Cumulative \% & $\%$ of variance & Cumulative \% & $\%$ of variance & Cumulative $\%$ \\
\hline 1 & 60.3 & 60.3 & 59.5 & 59.5 & 67.4 & 67.4 & 62.2 & 62.2 & 66.4 & 66.4 & 63.7 & 63.7 \\
\hline 2 & 21.5 & 81.8 & 22.9 & 82.4 & 18.9 & 86.3 & 20.5 & 82.7 & 17.7 & 84.1 & 19.9 & 83.6 \\
\hline 3 & 10.3 & 92.1 & 10.4 & 92.8 & 7.5 & 93.8 & 8.3 & 91.0 & 10.5 & 94.6 & 10.5 & 94.1 \\
\hline 4 & 3.7 & 95.8 & 3.4 & 96.2 & 3.2 & 97.0 & 4.9 & 95.9 & 2.9 & 97.5 & 3.3 & 97.4 \\
\hline 5 & 2.7 & 98.5 & 1.5 & 97.7 & 1.2 & 98.2 & 1.6 & 97.5 & 1.1 & 98.6 & 1.1 & 98.5 \\
\hline 6 & 0.5 & 99.0 & 1.1 & 98.8 & 1.0 & 99.2 & 1.0 & 98.5 & 0.6 & 99.2 & 0.9 & 99.4 \\
\hline 7 & 0.4 & 99.4 & 0.6 & 99.4 & 0.4 & 99.6 & 0.7 & 99.2 & 0.5 & 99.7 & 0.4 & 99.8 \\
\hline 8 & 0.3 & 99.7 & 0.4 & 99.8 & 0.2 & 99.8 & 0.5 & 99.7 & 0.2 & 99.9 & 0.1 & 99.9 \\
\hline 9 & 0.1 & 99.8 & 0.1 & 99.9 & 0.1 & 99.9 & 0.2 & 99.9 & & & & \\
\hline \multicolumn{13}{|l|}{10} \\
\hline \multicolumn{13}{|l|}{11} \\
\hline 12 & 0.2 & 100.0 & 0.1 & 100.0 & 0.1 & 100.0 & 0.1 & 100.0 & 0.1 & 100.0 & 0.1 & 100.0 \\
\hline \multicolumn{13}{|l|}{13} \\
\hline 14 & & & & & & & & & & & & \\
\hline
\end{tabular}


Table 5 Principal factor matrix after varimax rotation for 14 physiological factors of canola high oil content line (HOCL) and low oil content line (LOCL) canola from 2010 to 2012: numbers in bond are those with factors loading greater than $\mathbf{0 . 7 0}$ (absolute value)

\begin{tabular}{|c|c|c|c|c|c|c|c|c|c|c|c|c|c|c|c|c|c|c|}
\hline \multirow{2}{*}{$\begin{array}{l}\text { Physiological } \\
\text { parameters }\end{array}$} & \multicolumn{3}{|c|}{ HOCL 2010} & \multicolumn{3}{|c|}{ LOCL 2010} & \multicolumn{3}{|c|}{ HOCL 2011} & \multicolumn{3}{|c|}{ LOCL 2011} & \multicolumn{3}{|c|}{ HOCL 2012} & \multicolumn{3}{|c|}{ LOCL 2012} \\
\hline & $\mathrm{F} 1^{*}$ & F2* & F3* & $\mathrm{F} 1$ & F2 & F3 & $\mathrm{F} 1$ & F2 & F3 & $\mathrm{F} 1$ & F2 & F3 & $\mathrm{F} 1$ & F2 & F3 & $\mathrm{F} 1$ & F2 & F3 \\
\hline Fatty acids & -0.90 & 0.27 & -0.26 & -0.92 & -0.06 & -0.29 & -.085 & 0.34 & -0.33 & -0.86 & 0.16 & -0.45 & -0.55 & -0.80 & -0.24 & -0.74 & -0.64 & -0.15 \\
\hline Silique weight & -0.05 & 0.99 & -0.08 & -0.33 & 0.90 & -0.20 & -0.02 & 0.99 & -0.08 & 0.20 & 0.97 & -0.02 & -0.28 & -0.91 & -0.28 & -0.64 & -0.75 & -0.14 \\
\hline Seed weight & -0.24 & 0.91 & -0.24 & -0.50 & 0.78 & -0.30 & -.019 & 0.92 & -0.29 & -0.34 & 0.88 & -0.30 & -0.69 & -0.55 & -0.45 & -0.92 & -0.29 & -0.23 \\
\hline Total chlorophyll & 0.72 & -0.68 & 0.10 & 0.92 & -0.36 & 0.12 & 0.70 & -0.64 & 0.30 & 0.76 & -0.52 & 0.38 & 0.76 & 0.62 & -0.03 & 0.93 & 0.28 & -0.10 \\
\hline Silique fructose & 0.75 & 0.30 & 053 & 0.90 & 0.19 & 0.21 & 0.86 & 0.19 & 0.39 & 0.83 & -0.04 & 0.42 & 0.61 & 0.12 & 0.72 & 0.71 & 0.02 & 0.63 \\
\hline Seed fructose & 0.29 & -0.30 & 0.90 & 0.26 & -0.18 & 0.93 & 0.43 & -0.29 & 0.81 & 0.31 & -0.28 & 0.86 & 0.07 & 0.07 & 0.97 & 0.07 & 0.07 & 0.94 \\
\hline Silique glucose & 0.76 & 0.49 & 0.23 & 0.67 & 0.66 & 0.17 & 0.85 & 0.34 & 0.34 & 0.67 & 0.52 & 0.45 & 0.60 & 0.16 & 0.72 & 0.67 & 0.05 & 0.64 \\
\hline Seed glucose & 0.15 & -0.26 & 0.93 & 0.13 & -0.13 & 0.97 & 0.48 & -0.19 & 0.83 & 0.28 & -0.21 & 0.90 & 0.17 & 0.64 & 0.66 & 0.54 & 0.66 & 0.34 \\
\hline Silique sucrose & 0.69 & -0.69 & 0.17 & 0.87 & -0.43 & 0.15 & 0.62 & -0.77 & 0.09 & 0.59 & -0.60 & 0.32 & 0.66 & 0.62 & 0.42 & 0.90 & 0.36 & 0.19 \\
\hline Seed sucrose & 0.63 & -0.67 & 0.25 & 0.68 & -0.51 & 0.43 & 0.58 & -0.58 & 0.39 & 0.53 & -0.64 & 0.39 & 0.00 & 0.97 & 0.00 & 0.06 & 0.91 & -0.40 \\
\hline Silique starch & -0.02 & 0.84 & -0.26 & 0.36 & 0.84 & -0.09 & -0.01 & 0.67 & -0.62 & -0.22 & 0.81 & -0.24 & 0.78 & -0.57 & -0.07 & 0.15 & -0.94 & -0.20 \\
\hline Seed starch & 0.78 & -0.57 & 0.14 & 0.95 & -0.21 & 0.12 & 0.80 & -0.47 & 0.25 & 0.78 & -0.58 & -0.10 & 0.88 & 0.30 & 0.27 & 0.92 & 0.33 & 0.16 \\
\hline Silique cellulose & -0.91 & 0.13 & -0.11 & -0.90 & -0.19 & -0.10 & -0.90 & 0.36 & -0.13 & 0.93 & 0.16 & -0.30 & -0.91 & -0.14 & -0.32 & -0.93 & 0.21 & -0.17 \\
\hline Seed cellulose & -0.85 & 0.30 & -0.10 & -0.94 & 0.07 & -0.17 & -0.90 & 0.36 & -0.17 & 0.91 & 0.09 & -0.15 & -0.83 & -0.34 & -0.43 & -0.94 & 0.16 & -0.20 \\
\hline
\end{tabular}

*abbreviated for factor 1 (F1), factor 2 (F2), and factor 3 (F3).

low molecule sugars were found at this stage (Figures 5, 6, 7), which were also reported by Morley-Smith et al. (2008). The transient accumulation of these carbohydrates might be advantageous to take up enough water for extension force in a seed and hence increment of seed fresh weight. After embryo differentiated, liquid endosperm was quickly consumed by developing embryo and it rapidly occupied the most of the seed (Hill et al. 2003; Huang et al. 2009). Marked difference of silique fresh and dry weight during embryo development and lipid accumulation between HOCL and LOCL indicated that HOCL had larger capacity for water and materials such as sugar conservation and can be timely transported into seed for volume expansion. However, water potential of silique in different developmental stages should be further investigated. Notably, silique dry matter accumulated proportionally to fresh weight while there were some differences between seed dry matter and fresh weight accumulation. Although seed fresh weight kept very little fluctuation from 35 DAA to 55 DAA in 2010 and from 40 DAA to 55 DAA in 2011 (Figure 1B), it did not necessary mean that seed reached static balance. On the contrary, we interpret that there might be a homeostasis between matter exchanges. Firstly, liquid endosperm was rapidly absorbed by growing embryo and thus the embryo fresh weight was an alternative of original liquid endosperm weight. Secondly, when seed oil was forming, fructose and glucose decreased promptly at this period during the transformation of carbohydrates into lipids ( $\mathrm{He}$ and $\mathrm{Wu} 2009$; Figures 2, 3). However, regarding the relationship between seed weight and oil content, our result suggested that they were environmentally dependent (Table 1 and its contribution to seed oil content was not part of Factor 1 according to factor analysis (Tables 4 and 5). In Arabidopsis, Hobbs et al. (2004) reported that seed oil content was not significantly correlated with seed weight. Similar result was also observed in rapeseed that seed oil content was not significantly correlated with seed weight (Kennedy et al. 2011). However, we still propose that higher silique and seed fresh and dry weight during seed embryo development stage in HOCL could be an important basis for obtaining high seed oil content. A lower capacity of sugars loading from silique to the seed is likely to reduce the amount of substrate for oil biosynthesis. Furthermore, high seed oil content with high seed weight is desirable for seed oil yield.

As silique and seed development, both of them accumulated high chlorophyll content (Figure 4 and Additional file 1: Figure S1). However, the former has been considered as a pivotal photosynthetic organ after flowering (Chung et al. 2006; Gammelvind et al. 1996). Thus, we correspondingly monitored developing silique chlorophyll content from 2010 to 2012. Furthermore, seed chloroplast morphology was not the same to that of silique. The area of starch grain in seed cell was larger than that in silique (Figure 3A). Previous investigation showed that sun-type chloroplast contained large starch grains while shade-type chloroplast contained no starch (Lichtenthaler et al. 1981; Lichtenthaler and Burkart 1999). Given the developing seeds was in dark or weak light condition, it is surprising that seed cell contained large starch grain. The chlorophyll content in both lines declined continuously. Significantly higher content throughout the developmental stages 
(Figure 4 and Additional file 1: Figure S1) in HOCL indicated its high ability to produce more photoassimilates (Lichtenthaler et al. 1981). In Arabidopsis, silique also accumulates chlorophyll at very early stage (before 8 DAA) and then declined quickly, which resembled with oilseed rape (Wagstaff et al. 2009 and our result). Furthermore, during silique senescence, lots of genes involved in carbohydrate metabolism are upregulated accompanying the decreasing chlorophyll content (Wagstaff et al. 2009). However, regardless of higher silique carbohydrate content in HOCL, it is not certain that expression of corresponding carbohydrate related genes are really higher than that in LOCL during rapeseed seed development. Interestingly, both correlation and factor analysis suggested its importance to the seed oil content (Tables 1, 2, 3, 4, 5). Thus, postponing the senescence of silique could increase seed oil production.

After carbohydrate was produced in the developing silique, function of sugar in the seed should depend on its developmental schedule. Carbohydrates were important osmotic solutes in silique and seed and were involved in the compound transformation into lipid. Despite of the importance of carbohydrate during lipid biosynthesis, some researchers noticed that the function of sugar might be magnified because the amount of sugar was far less than that of lipid (Andriotis et al. 2010). However, this debate could not weaken the role of carbohydrate in this process. Previous research work has suggested that carbohydrate content in seed was closely correlated with oil content (Focks and Benning 1998; Tan et al. 2011). Relationship between carbohydrate accumulation and lipid biosynthesis should be split into two ways: 1.) carbohydrate as initial substrate for lipid synthesis (White et al. 2000); 2.) transformation efficiency from carbohydrate to lipid involved many related enzymes (Marillia et al. 2003; Gómezi et al. 2006; Ekman et al. 2008; Wakao et al. 2008). For instance, a reduction of $80 \%$ of seed oil content was found due to a dysfunction of carbohydrate metabolism, especially for the transformation of sucrose and glucose into lipid in wrinke 1 mutant (Focks and Benning 1998). Hence, both ways can affect seed oil content.

Among these carbohydrates, hexoses content was largely and consistently higher than that of sucrose and starch at early developmental stage both under fresh and dry weight condition in silique (Figures 5, 6, 7, 8, 9), which was in accordance with previous study (King et al. 1997). Morley-Smith et al. (2008) reported that sucrose rapidly converted into hexoses after entering into seeds at early stage and kept high ratio of hexose-to-sucrose, which could explain of our results. Fructose and glucose are the low weight molecules in cells and directly take part in the lipid synthesis in seed and other metabolic pathways in silique (Chen et al. 2009), so higher content of fructose and glucose could be quickly utilized once they entered seed from silique. Unlike fructose and glucose, sucrose was always cleaved into fructose and glucose by either invertase or sucrose synthase or both (Fu et al. 1995; Ekman et al. 2008). In this study, sucrose content at early flowering stage was higher than that at late flowering stage in both HOCL and LOCL (Figure 7). Though part of the carbohydrate in silique would be transported into seed, it should retain certain amount of carbohydrate for its own development. Thus higher carbohydrate at early flowering stage is necessary because the carbohydrate content is beneficial for osmotic potential maintaining and promoting water uptake and cell elongation (Wang et al. 2000; Lalonde et al. 2003). As a result, high content of sucrose guaranteed rapid silique elongation at early developmental stages. Generally, sucrose content was in a much low level of silique tissue as comparison with seed though HOCL was significant higher than LOCL (Figure 7). The state of low sucrose content might suggest the high frequency for sucrose cleavage. It was found that very high sucrose synthase activity was observed in Arabidopsis and canola silique (King et al. 1997; Fallahi et al. 2008). A possible role of sucrose cleavage by sucrose synthase was suggested for energy supply for the phloem transport activity (Fallahi et al. 2008). Nevertheless, for the purpose of sucrose cleavage, high efficiency of sucrose utilization was evident in silique tissue both in high and low oil content lines. Sucrose was also catalyzed into UDPglucose for starch and cellulose synthesis (Geigenberger 2003; Hajirezaei et al. 2003). It was proved that starch is not the dominant carbohydrate type in silique (King et al. 1997; Andriotis et al. 2010). Furthermore, starch grains were observed in the funiculus and seed coat during early seed development of Arabidopsis through chemical staining in silique section suggesting silique starch might be mainly transported into seed rather for participated in other silique physiological metabolism (Fallahi et al. 2008). Alternatively, although starch had function for storage, the starch content almost disappeared during oil synthesis in canola seed, thus it was suggested that starch is preferentially involved into cell division or differentiation (Fallahi et al. 2008; Andriotis et al. 2010). However, there were also studies supporting the opinion that starch content can influence oil content directly (Fan et al. 2012, Meyer et al. 2012). For example, prohibiting from starch biosynthesis can promote the rate of oil biosynthesis in a starchless mutant Chlamydomonas reinhardtii, BAFJ5 (Fan et al. 2012). Interestingly, a cDNA fragment encoded ADP-Glc pyrophosphorylase, which was driven under embryo-specific promoter, was expressed in the antisense model in oilseed rape. The result showed that both of the starch and lipid content was reduced in the developing seed while no significant difference of oil content at maturation stage (Vigeolas 
et al. 2004). This phenomenon implied that oilseed rape embryo should have compensation way(s) to increase seed oil content finally through bypassing the reduction of starch synthesis. In our experiment, both correlation and factor analysis revealed the importance of seed starch content to seed oil content. Because hexoses mainly accumulated at seed liquid endosperm stage and sucrose was cleaved into hexoses, starch content was relatively higher among these sugars and should be the major carbon source for seed lipid deposition (Figures 5, 6, 7, 8). Moreover, many starch grains were contained in the chloroplast in the seed cells, larger number of chloroplasts in the seed cells of HOCL should be a key factor to accumulate more lipids during seed development. Consequently, regardless of degradation of starch, its relatively higher content may be tightly associated with lipid synthesis especially in developing seeds of HOCL.

The close relationship between cellulose content and seed oil content indicated that reduction of cellulose content to some extent should be beneficial for improving seed oil content. Another implication is that the thinner cell wall in silique might allow more light to penetrate, thus possibly to enhance seed photosynthesis as other studies suggested seed is also an important photosynthetic organ (Eastmond et al. 1996).

\section{Conclusion}

Taken together, our investigation clearly revealed the large variation of silique and seed physiological parameters in canola lines with different seed oil content, indicating the effect of silique physiological indexes on seed oil accumulation. In this study, we suggested that carbohydrates play crucial roles in rapid organ expansion at early seed developmental stage. After embryo differentiation, the main function of carbohydrate took part in lipid biosynthesis. One of the major distinction during seed development was the higher accumulation of oil body in HOCL while more protein accumulation in LOCL in the seed cell. Increasing silique chlorophyll and seed starch content while decreasing silique and seed cellulose content may be beneficial to increase seed oil content. Furthermore, silique physiological parameters should be adopted not only by physiologists but also by agronomists to assist canola breeding programs towards to super higher seed oil content.

\section{Additional file}

Additional file 1: Figure S1. Dynamic chlorophyll content in developing seed of canola high oil content line (HOCL) and low oil content line (LOCL) from 10 to 65 days after anthesis (DAA) at a 5-day interval in 2012. Each value is the mean of seeds from 15 main-inflorescence siliques of five plants from each of three replicate plots. Error bars represent standard errors. " "* at each developmental stage indicates a significant difference at 5\% probability between HOCL and LOCL in both years.

\section{Abbreviations}

DAA: Days after anthesis; DW: Dry weight; FW: Fresh weight; GC: Gas chromatography; HOCL: High oil content line; LOCL: Low oil content line; RILs: Recombinant Inbred Lines; TEM: Transmission electron microscopy.

\section{Competing interests}

The authors declare that they have no competing interests.

\section{Authors' contributions}

HS experimental design, TEM assay, data analysis, and manuscript writing: $C Z$, data analysis, manuscript writing; ZY, fresh and dry weight, seed oil content, and profiles of fatty acid measurement; YH and LB carbohydrate and chlorophyll content determination; ZD plant materials supply and experimental design. All authors read and approved the final manuscript.

\section{Acknowledgements}

This work was supported by Zhejiang Academy of Agricultural Sciences Special Fund (Zheyou 50), the key projects in the national science \& technology pillar program during the eleventh five-year plan period "Breeding of the canola variety with high oil content and yield suitable for mechanization", partially by the Modern Agricultural Technology System Program of China (MATS: nycytx-005), "The key and integrated technology for canola high yield improvement", Project of Zhejiang Province Innovation Group "Technology innovation group for dry land crops, food, and oil crops-creation for elite germplasms in rapeseed (2011R50026-04 and 2012(12902-1)", and special fund for Ago-scientific Research in the Public Interest (201103007). Z.-H.C. was supported by a Research Lectureship of University of Western Sydney, Australia.

\section{Author details}

${ }^{1}$ Institute of Crop and Nuclear Technology Utilization, Zhejiang Academy of Agricultural Sciences, Hangzhou 310021, P.R. China. ${ }^{2}$ School of Science and Health, University of Western Sydney, Penrith 2751NSW, Australia.

Received: 1 April 2013 Accepted: 3 December 2013

Published: 19 March 2014

\section{References}

Agrawal GK, Hajduch M, Graham K, Thelen JJ (2008) In-Depth investigation of soybean seed-filling proteome and comparison with a parallel study of rapeseed. Plant Physiol 148:504-518

Andre C, Froehlich JE, Moll MR, Benning C (2007) A heteromeric plastidic pryruvate kinase complex involved in seed oil biosynthesis in Arabidopsis. Plant Cell 19:2006-2022

Andriotis VME, Pike MJ, Kular B, Rawsthorne S, Smith AM (2010) Starch turnover in developing oilseed embryos. New Phytol 187:791-804

Baud S, Lepiniec $L$ (2009) Regulation of de novo fatty acid synthesis in maturing oilseeds of Arabidopsis. Plant Physiol Biochem 47:448-455

Berry PM, Spink JH (2006) A physiological analysis of oilseed rape yields: past and future. J Agric Sci 144:381-392

Bennett EJ, Roberts JA, Wagstaff C (2011) The role of pod in seed development: strategies for manipulating yield. New Phytol 190:838-853

Cheema MA, Malik MA, Hussain A, Shah SH, Basra SMA (2001) Effects of time and rate of nitrogen and phosphorus application on growth and the seed and oil yield in canola (Brassica napus L.). J Agron Crop Sci 186:103-110

Chen M, Mooney BP, Hajduch M, Joshi T, Zhou M, Xu D, Thelen JJ (2009) System analysis of an Arabidopsis mutant altered in de novo fatty acid synthesis reveals diverse changes in seed composition and metabolism. Plant Physiol 150:27-41

Chen M, Wang Z, Zhu Y, Li Z, Hussain N, Xuan L, Guo W, Zhang G, Jiang L (2012) The effect of TRANSPARENT TESTAR2 on seed fatty acid biosynthesis and tolerance to environmental stresses during young seedling establishment in Arabidopsis. Plant Physiol 160:1023-1036

Child RD, Summers JE, Babij J, Farrent JW, Bruce DM (2003) Increased resistance to pod shatter with changes in the vascular structure in pods of a resynthesized Brassica napus line. J Exp Bot 54:1919-1930

Chung DW, Pružinská A, Hörtensteiner S, Ort DR (2006) The role of pheophorbide a oxygenase expression and activity in the canola green seed problem. Plant Physiol 142:88-97

Delourme R, Falentin C, Huteau V, Clouet V, Horvais R, Gandon B, Specel S, Hanneton L, Dheu JE, Descuhamps M, Margale E, Vincourt P, Renard M 
(2006) Genetic control of oil content in oilseed rape (Brassica napus L.). Theor Appl Genet 113:1331-1345

Dubousset L, Etienne P, Avice JC (2010) Is the remobilization of S and N reserves for seed filling of winter oilseed rape modulated by sulphate restrictions occurring at different growth stages? J Exp Bot 61:4313-4324

Eastmond P, Koláčná L, Rawsthorne S (1996) Photosynthesis by developing embryos of oilseed rape (Brassica napus L.). J Exp Bot 47:1763-1769

Ekman Å, Hayden DM, Dehesh K, Bülow L, Stymne S (2008) Carbon partitioning between oil and carbohydrates in developing oat (Avena sativa L.) seeds. J Exp Bot 59:4247-4257

Fallahi H, Scofield GN, Badger MR, Chow WS, Furbank RT, Ruan Y (2008) Localization of sucrose synthase in developing seed and silique of Arabidopsis thaliana reveals diverse roles for SUS during development. J Exp Bot 59:3283-3295

Fan J, Yan C, Andre C, Shanklin J, Schwender J, Xu C (2012) Oil accumulation is controlled by carbon precursor supply for fatty acid sytnehsis in Chlamydomonas reinhardtii. Plant Cell Physiol 53:380-1390

Focks N, Benning C (1998) Wrinkled 1: A novle, low-seed-oil mutant of Arabidopsis with a deficiency in the seed-specific regulation of carbohydrate metabolism. Plant Physiol 118:91-101

Fu H, Kim SY, Park WD (1995) A potato Sus3 sucrose synthase gene contains a context-dependt $3^{\prime}$ element and a leader intron with both positive and negative tissue-specific effects. Plant Cell 7:1395-1403

Gammelvind LH, Schjoerring JK, Mogensen VO, Jensen CR, Bock JGH (1996) Photosynthesis in leaves and siliques of winter oilseed rape (Brassica napus L.). Plant Soil 186:227-236

Gan Y, Malhi SS, Brandt SA, Mcdonald CL (2008) Assessment of seed shattering resistance and yield loss in five oilseed crops. Can J Plant Sci 88:267-270

Geigenberger P (2003) Regulation of sucrose to starch conversion in growing potato tubers. J Exp Bot 54:457-465

Gómezi LD, Baud S, Gilday A, Graham IA (2006) Delayed embryo development in the ARABIDOPSIS TREHALOSE-6-PHOSPHATE SYNTHASE 1 mutant is associated with altered cell wall structure, decreased cell division and starch accumulation. Plant J 46:69-84

Hajduch M, Casteel JE, Hurrelmeyer KE, Song Z, Agrawal GK, Thelen JJ (2006) Proteomic analysis of seed filling in Brassica napus. developmental characterization of metabolic isozymes using high-resolution twodimensional gel electrophoresis. Plant Physiol 141:32-46

Hajduch M, Hearne LB, Miernyk JA, Casteel JE, Joshi T, Agrawal GK, Song Z, Zhou MY, Xu D, Thelen JJ (2010) Systems analysis of seed filling in Arabidopsis: using general linear modeling to assess concordance of transcript and protein expression. Plant Physiol 152:2078-2087

Hajirezaei M, Börnke F, Peisker M, Takahata Y, Lerchl J, Kirakosyan A, Sonnewald U (2003) Decreased sucrose content triggers starch breakdown and respiration in stored potato tubers (Solanum tuberosum). J Exp Bot 54:477-488

He Y, Wu Y (2009) Oil body biogenesis during Brassica napus embryogenesis. J Integr Plant Biol 51:792-799

Hendrix DL (1993) Rapid extraction and analysis of nonstructural carbohydrates in plant tissues. Crop Sci 33:1306-1311

Hill M, Morley-Smith ER, Rawsthorne S (2003) Metabolism of sugars in the endosperm of developing seeds of oilseed rape. Plant Physiol 131:228-236

Hobbs DH, Flintham JE, Hills MJ (2004) Genetic control of storage oil synthesis in seeds of Arabidopsis. Plant Physiol 136:3341-3349

Houston NL, Hajduch M, Thelen JJ (2009) Quantitative proteomics of seed filling in castor: comparison with soybean and rapeseed reveals differences between photosynthetic and nonphotosynthetic seed metabolism. Plant Physiol 151:857-868

Hua S, Yu H, Zhang Y, Lin B, Ding H, Zhang D, Ren Y, Chen Z-H (2012a) Variation of biomass, carbohydrate, and nutrient content variation in canola (Brasscia napus L.) plants with contrasting seed oil content. Aust J Crop Sci 6:1275-1282

Hua W, Li R, Zhan G, Liu J, Li J, Wang XF, Liu GH, Wang HZ (2012b) Maternal control of seed oil content in Brassica napus: the role of silique photosynthesis. Plant J 69:432-444

Huang Y, Chen L, Wang L, Vijayan K, Phan S, Liu Z, Wan L, Ross A, Xiang D, Datla R, Pan Y, Zou J (2009) Probing the endosperm gene expression landscape in Brassica napus. BMC Genomics 10:256-274

Jenkins ES, Paul W, Coupe SA, Bell SJ, Davies EC, Robert JA (1996) Characterization of an mRNA encoding a polygalacturonase expressed during pod development in oilseed rape (Brassica napus L.). J Exp Bot 47:111-115

Johnson-Flanagan AM, Zhong H, Geng X, Brown DCW, Nykiforuk CL (1992) Frost, abscisic acid, and desiccation hasten embryo development in Brassica napus. Plant Physiol 99:700-706
Kennedy Y, Yokoi S, Sato T, Daimon H, Nishida I, Takahata Y (2011) Genetic variation of storage compounds and seed weight in rapeseed (Brassica napus L.) germplasms. Breed Sci 61:311-315

King SP, Lunn JE, Furbank RT (1997) Carbohydrate content and enzyme metabolism in developing canola silique. Plant Physiol 114:153-160

Lalonde S, Tegeder M, Thorone-Holst M, Frommer WB, Patrick JW (2003) Phloem loading and unloading of sugars and amino acids. Plant Cell Environ 26:37-56 Lewis GJ, Thruling N (1994) Growth, development, and yield of three oilseed Brassica species in a water-limited environment. Aust J Exp Agric 34:93-103

Lichtenthaler HK (1987) Chlorophylls and carotenoids: pigments and photosynthetic biomembranes. Method Enzymol 148:350-382

Lichtenthaler HK, Burkart S (1999) Photosynthesis and high light stress. Bulg J. Plant Physiol 25:3-16

Lichtenthaler HK, Buschmann C, Döll M, Fietz HJ, Bach T, Kozel U, Meier D, Rahmsdore U (1981) Photosynthetic activity, chloroplast ultrastructure, and leaf characteristics of high-light and low-light plants of and sun and shade leaves. Photosynth Res 2:115-141

Louvet R, Rayon C, Domon JM, Rusterucci C, Fournet F, Leaustic A, Crepeau MJ, Ralet MC, Rihourey C, Bardor M, Lerouge P, Gillet F, Pelloux J (2011) Major changes in the cell wall during silique development in Arabidopsis thaliana. Phytochemistry 72:59-67

Marillia E, Micallef BJ, Micallef M, Weninger A, Pedersen KK, Zou J, Taylor DC (2003) Biochemical and physiological studies of Arabidopsis thaliana transgenic lines with repressed expression of the mitochondrial pyruvate dehydrogenase kinase. J Exp Bot 54:259-270

Mccutchan CL, Monson RK (2001) Night-time respiration rate and leaf carbohydrate concentrations are not coupled in two alpine perennial species. New Phytol 149:419-430

Meyer K, Stecca KL, Ewell-Hicks K, Allen SM, Everard JD (2012) Oil and protein accumulation in developing seeds is influenced by the expression of cytosolic pyrophosphatase in Arabidopsis. Plant Physiol 159:1221-1234

Morley-Smith ER, Pike MJ, Findlay K, Köchenberger W, Hill LM, Smith AM, Rawsthorne $S$ (2008) The transport of sugars to developing embryos is not via the bulk endosperm in oilseed rape seeds. Plant Physiol 147:2121-2130

Mu J, Tan H, Zhen Q, Fu F, Liang Y, Zhang J, Yang X, Wang T, Chong K, Wang X, Zuo J (2008) LEAFY COTYLEDON1 is a key regulator of fatty acid biosynthesis in Arabidopsis. Plant Physiol 148:1042-1054

Rathke GW, Behrene T, Diepenbrock W (2006) Integrated nitrogen management strategies to improve seed yield, oil content and nitrogen efficiency of winter oilseed rape (Brassica napus L.): A review. Agr Ecosyst Environ 117:80-108

Rossato L, Lainé P, Ourry A (2001) Nitrogen storage and remobilization in Brassica napus $L$. during the growth cycle: nitrogen fluxes within the plant and changes in soluble protein patterns. J Exp Bot 52:1623-1655

Ruuska SA, Girke T, Benning C, Ohlrogge JB (2002) Contrapuntal networks of gene expression during Arabidopsis seed filling. Plant Cell 14:1191-1206

Stadler R, Lauterbach C, Sauer N (2005) Cell-to-cell movement of green fluorescent protein reveals post-phloem transport in the outer integument and identifies symplastic domains in Arabidopsis seeds and embryos. Plant Physiol 139:701-712

Tan H, Yang X, Zhang F, Zheng X, Qu C, Mu J, Fu F, Li J, Guan R, Zhang H, Wang G, Zuo J (2011) Enhanced seed oil production in canola by conditional expression of Brassica napus LEAFY COTYLEDON1 and LEC1-LIKE in developing seeds. Plant Physiol 156:1577-1588

Updegraff DM (1969) Semimicro determination of cellulose in biological materials. Anal Biochem 32:420-424

Vigeolas H, Möhlmann T, Martini N, Neuhaus HE, Geigengerger P (2004) Embryo-specific reduction of ADP-Glc phyrophosphorylase leads to an inhibition of starch synthesis and a delay in oil accumulation in developing seed of oilseed rape. Plant Physiol 136:2676-2686

Wagstaff C, Yang TJW, Stead AD, Buchanan-Wollaton V, Roberts JA (2009) A molecular and structural characterization of senescing Arabidopsis siliques and comparison of transcriptional profiles with senescing petals and leaves. Plant J 57:690-705

Wakao S, Andre C, Benning C (2008) Functional analysis of cytosolic glucose-6phosphate dehydrogenases and their contribution to seed oil accumulation in Arabidopsis. Plant Physiol 146:277-288

Wang H, Lee P, Chen W, Huang D, Su J (2000) Osmotic-stress induced changes of sucrose metabolism in cultured sweet potato cells. J Exp Bot 51:1991-1999

Wang HY, Guo JH, Lambert KN, Lin Y (2007a) Developmental control of Arabidopsis seed oil biosynthesis. Planta 226:773-783 
Wang R, Ripley VL, Rakow G (2007b) Pod shatter resistance evaluation in cultivars and breeding lines of Brassica napus, B. juncea and Sinapis alba. Plant Breed 126:588-595

Wang XF, Liu GH, Yang Q, Hua W, Liu J, Wang HZ (2010) Genetic analysis on oil content in rapeseed (Brassica napus L.). Euphytica 173:17-24

White JA, Todd J, Newman T, Focks N, Girke T, De llárduya OM, Jaworski JG, Ohlrogge JB, Benning C (2000) A new set of Arabidopsis expressed sequence tags from developing seeds. The metabolism pathway from carbohydrate to seed oil. Plant Physiol 124:1582-1594

Yang P, Shu C, Chen L, Xu J, Wu J, Liu K (2012) Identification of a major QTL for silique length and seed weight in oilseed rape (Brassica napus L.). Theor Appl Genet 125:285-296

Zhang L, Yang G, Liu P, Hong D, Li S, He Q (2011) Genetic and correlation analysis of silique-traits in Brassica napus L. by quantitative trait locus mapping. Theor Appl Genet 122:21-31

doi:10.1186/1999-3110-55-34

Cite this article as: Hua et al: Chlorophyll and carbohydrate metabolism

in developing silique and seed are prerequisite to seed oil content of

Brassica napus L.. Botanical Studies 2014 55:34.

\section{Submit your manuscript to a SpringerOpen ${ }^{\circ}$} journal and benefit from:

- Convenient online submission

- Rigorous peer review

- Immediate publication on acceptance

- Open access: articles freely available online

- High visibility within the field

- Retaining the copyright to your article

Submit your next manuscript at $>$ springeropen.com 